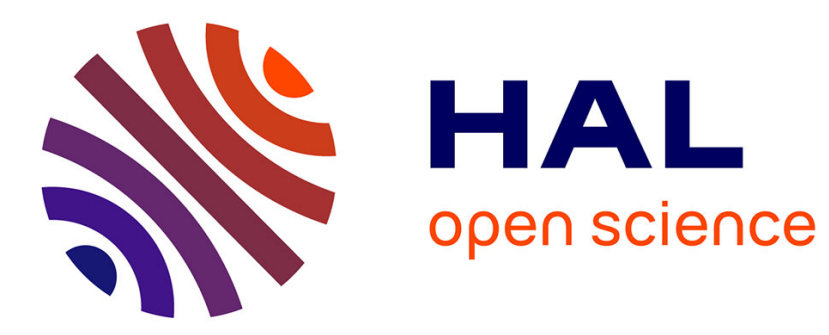

\title{
Cannabidiol Inhibits Cancer Cell Invasion Via Upregulation Of Tissue Inhibitor Of Matrix Metalloproteinases-1
}

Robert Ramer, Jutta Merkord, Helga Rohde, Burkhard Hinz

\section{> To cite this version:}

Robert Ramer, Jutta Merkord, Helga Rohde, Burkhard Hinz. Cannabidiol Inhibits Cancer Cell Invasion Via Upregulation Of Tissue Inhibitor Of Matrix Metalloproteinases-1. Biochemical Pharmacology, 2010, 79 (7), pp.955. 10.1016/j.bcp.2009.11.007 . hal-00560684

\section{HAL Id: hal-00560684 https://hal.science/hal-00560684}

Submitted on 29 Jan 2011

HAL is a multi-disciplinary open access archive for the deposit and dissemination of scientific research documents, whether they are published or not. The documents may come from teaching and research institutions in France or abroad, or from public or private research centers.
L'archive ouverte pluridisciplinaire HAL, est destinée au dépôt et à la diffusion de documents scientifiques de niveau recherche, publiés ou non, émanant des établissements d'enseignement et de recherche français ou étrangers, des laboratoires publics ou privés. 


\section{Accepted Manuscript}

Title: Cannabidiol Inhibits Cancer Cell Invasion Via Upregulation Of Tissue Inhibitor Of Matrix

Metalloproteinases-1

Authors: Robert Ramer, Jutta Merkord, Helga Rohde, Burkhard Hinz

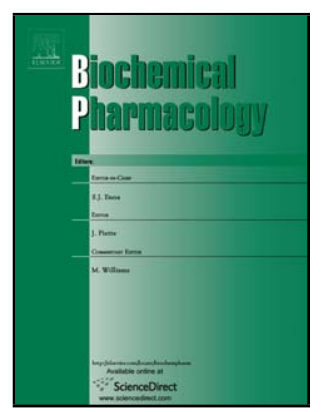

PII: S0006-2952(09)00971-X

DOI: doi:10.1016/j.bcp.2009.11.007

Reference: BCP 10379

To appear in: $\quad B C P$

Received date: $\quad$ 9-7-2009

Revised date: 5-11-2009

Accepted date: 6-11-2009

Please cite this article as: Ramer R, Merkord J, Rohde H, Hinz B, Cannabidiol Inhibits Cancer Cell Invasion Via Upregulation Of Tissue Inhibitor Of Matrix Metalloproteinases-1, Biochemical Pharmacology (2008), doi:10.1016/j.bcp.2009.11.007

This is a PDF file of an unedited manuscript that has been accepted for publication. As a service to our customers we are providing this early version of the manuscript. The manuscript will undergo copyediting, typesetting, and review of the resulting proof before it is published in its final form. Please note that during the production process errors may be discovered which could affect the content, and all legal disclaimers that apply to the journal pertain. 


\title{
CANNABIDIOL INHIBITS CANCER CELL INVASION VIA UPREGULATION OF TISSUE INHIBITOR OF MATRIX METALLOPROTEINASES-1 ${ }^{\#}$
}

\author{
Robert Ramer, Jutta Merkord, Helga Rohde and Burkhard Hinz ${ }^{1}$ \\ Institute of Toxicology and Pharmacology, University of Rostock, Schillingallee 70, D-18057 \\ Rostock, Germany \\ ${ }^{1}$ To whom correspondence should be addressed: \\ Dr. Burkhard Hinz \\ Institute of Toxicology and Pharmacology \\ University of Rostock \\ Schillingallee 70 \\ D-18057 Rostock \\ Germany \\ PHONE: +49-381-4945770 \\ FAX: +49-381-4945772 \\ E-MAIL: burkhard.hinz@med.uni-rostock.de \\ \# This study was supported by grants from the Deutsche Krebshilfe e. V. (Bonn, Germany), \\ Deutsche Forschungsgemeinschaft (SFB 539 TP BI.6) and the FORUN programme of the \\ Medical Faculty of the University of Rostock
}

Running title: Inhibition of cancer cell invasion by cannabidiol 


\section{Abstract}

Although cannabinoids exhibit a broad variety of anticarcinogenic effects, their potential use in cancer therapy is limited by their psychoactive effects. Here we evaluated the impact of cannabidiol, a plant-derived non-psychoactive cannabinoid, on cancer cell invasion. Using Matrigel invasion assays we found a cannabidiol-driven impaired invasion of human cervical cancer (HeLa, C33A) and human lung cancer cells (A549) that was reversed by antagonists to both $\mathrm{CB}_{1}$ and $\mathrm{CB}_{2}$ receptors as well as to transient receptor potential vanilloid 1 (TRPV1). The decrease of invasion by cannabidiol appeared concomitantly with upregulation of tissue inhibitor of matrix metalloproteinases-1 (TIMP-1). Knockdown of cannabidiol-induced TIMP-1 expression by siRNA led to a reversal of the cannabidiol-elicited decrease in tumor cell invasiveness, implying a causal link between the TIMP-1-upregulating and anti-invasive action of cannabidiol. P38 and p42/44 mitogen-activated protein kinases were identified as upstream targets conferring TIMP-1 induction and subsequent decreased invasiveness. Additionally, in vivo studies in thymic-aplastic nude mice revealed a significant inhibition of A549 lung metastasis in cannabidiol-treated animals as compared to vehicle-treated controls. Altogether, these findings provide a novel mechanism underlying the anti-invasive action of cannabidiol and imply its use as a therapeutic option for the treatment of highly invasive cancers. 
Keywords: cannabidiol, Matrigel cell invasion, tissue inhibitor of matrix metalloproteinases-1, human cancer cells, experimental lung metastasis

\begin{abstract}
Abbreviations: AM-251, N-(Piperidin-1-yl)-5-(4-iodophenyl)-1-(2,4-dichlorophenyl)-4-methyl1H-pyrazole-3-carboxamide; AM-630, (6-lodo-2-methyl-1-[2-(4-morpholinyl)ethyl]-1H-indol-3yl) (4-methoxyphenyl)methanone; cannabidiol, 2-((1S,6S)-3-methyl-6-(prop-1-en-2-yl) cyclohex-2-enyl)-5-pentylbenzene-1,3-diol; $\mathrm{CB}_{1}$, cannabinoid receptor 1 ; $\mathrm{CB}_{2}$, cannabinoid receptor 2; DMSO, dimethyl sulfoxide; EDTA, ethylenediaminetetraacetic acid; HEPES, 4-(2hydroxyethyl)-1-piperazineethanesulfonic acid; MAPK, mitogen-activated protein kinase; MMP, matrix metalloproteinase; PMSF, phenylmethylsulfonyl fluoride; RT-PCR, reverse transcriptase-polymerase chain reaction; siRNA, small-interfering RNA; THC, $\Delta^{9}-$ tetrahydrocannabinol; TIMP, tissue inhibitor of matrix metalloproteinase; TRPV1, transient receptor potential vanilloid 1; WST-1, 4-[3-(4-lodophenyl)-2-(4-nitrophenyl)-2H-5-tetrazolio]1.6-benzene disulfonate
\end{abstract}




\section{Introduction}

During the last decade several cell culture and animal studies have provided a great body of evidence for an antitumorigenic action of cannabinoids on the levels of cancer cell proliferation [1,2], apoptosis [3,4], metastasis [5], and angiogenesis [6-8]. Although cannabinoid-based drugs such as $\Delta^{9}$-tetrahydrocannabinol (THC) are clinically used to palliate wasting, emesis and pain in cancer patients, a shortcoming for these and forthcoming indications clearly lies in the psychoactive adverse side effects of cannabinoids. For this reason, the interest in the non-psychoactive cannabinoid-mimetic compound cannabidiol has substantially increased in recent years. Meanwhile, a formulation including a 1:1 ratio of THC and cannabidiol has been approved for the pharmacotherapy of multiple sclerosis-related spasticity and pain in Canada [9].

The precise mechanism by which cannabidiol exerts its biological effects is still a matter of debate. Although cannabidiol displays a low affinity to $\mathrm{CB}_{1}$ and $\mathrm{CB}_{2}$ receptors [10], several effects of cannabidiol including modulation of cytokine release and macrophage chemotaxis [11], antiproliferative [12] as well as proapoptotic properties [13] have been shown to be mediated via $\mathrm{CB}_{1}$ and/or $\mathrm{CB}_{2}$ receptors. In other investigations, cannabidiol has even been reported to display antagonistic effects on $\mathrm{CB}_{1}$ and $\mathrm{CB}_{2}$ receptor [14], as well as synergistic effects on THC-mediated hypoactivity, hypothermia and impairment of spatial memory [15]. On the other hand increasing evidence suggests an indirect receptor activation by cannabidiol. In this context an inhibitory action on fatty acid amidohydrolase activity that confers release of anandamide and increased receptor-mediated signalling by this endocannabinoid has been demonstrated in diverse systems [16-18]. Additionally, the nonselective cation channel transient receptor potential 1 (TRPV1) was shown to be involved in cannabidiol-mediated antihyperalgesia [19] and inhibition of cancer cell proliferation [17]. Finally, diverse studies suggest the involvement of a hitherto undefined abnormal cannabidiol receptor in several actions of cannabidiol (for review see [20]). 
In context with the antitumorigenic action of cannabinoids, modulation of cancer cell invasion

has recently emerged as a topic of increasing interest [21-23]. Cancer cell invasion is a complex process of cell locomotion through degraded matrix components of microenvironmental spaces surrounding a tumor thereby contributing to tumor cell metastasis and angiogenesis. The level of tumor invasiveness and malignancy is mainly determined by a sensitive balance between collagen- and proteoglycan-degrading matrix metalloproteinases (MMPs) and their endogenous inhibitors, the tissue inhibitors of MMPs (TIMPs) (for review see ref. [24]). Among the four distinct members of the TIMP family, elevated TIMP-1 was shown to mediate the anti-invasive effects of several anticarcinogenic drugs [23,25-29]. Furthermore, decreased TIMP-1 levels were demonstrated to correlate with high cancer invasiveness [30,31].

The present study focussed on a potential role of TIMP-1 upregulation in the anti-invasive action of cannabidiol and on a possible involvement of cannabinoid receptors and TRPV1 in this process. In view of recent studies demonstrating p38 and p42/44 mitogen-activated protein kinases (MAPK) activation as intracellular signaling pathways leading to induction of TIMP-1 $[32,33]$ as well as findings showing a cannabinoid receptor-dependent activation of MAPKs $[3,34,35]$, our study also assessed a role of both MAPKs in cannabidiol-modulated invasion and TIMP-1 expression. Finally, the impact of cannabidiol on cellular invasion was confirmed by studying metastasis in vivo. 


\section{Materials and methods}

\section{Materials}

(-)-Cannabidiol was purchased from Tocris (Bad Soden, Germany). AM-251, AM-630, capsazepine, PD98059 and SB203580 were bought from Alexis Deutschland GmbH (Grünberg, Germany). Dulbecco's Modified Eagle's medium (DMEM) with 4 mM L-glutamine and $4.5 \mathrm{~g} / \mathrm{L}$ glucose was from Cambrex Bio Science Verviers S.p.r.l. (Verviers, Belgium). Fetal calf serum (FCS) and penicillin-streptomycin were obtained from PAN Biotech (Aidenbach, Germany) and Invitrogen (Karlsruhe, Germany), respectively. DMSO, HEPES, $\mathrm{NaCl}$, EDTA, Triton ${ }^{\oplus} \mathrm{X}-100$, and glycerol were bought from Applichem (Darmstadt, Germany). PMSF, leupeptin, aprotinin and picrinic acid, and formaldehyde were obtained from Sigma (Taufkirchen, Germany).

\section{Cell culture}

HeLa, C33A and A549 cells were maintained in DMEM supplemented with 10\% heatinactivated FCS, $100 \mathrm{U} / \mathrm{ml}$ penicillin, and $100 \mu \mathrm{g} / \mathrm{ml}$ streptomycin. The cells were grown in a humidified incubator at $37^{\circ} \mathrm{C}$ and $5 \% \mathrm{CO}_{2}$. All incubations were performed in serum-free medium. Phosphate-buffered saline was used as a vehicle for the tested substances with a final concentration of $0.1 \%(\mathrm{v} / \mathrm{v})$ ethanol (for cannabidiol) or $0.1 \%(\mathrm{v} / \mathrm{v})$ dimethyl sulfoxide (DMSO) (for AM-251, AM-630, capsazepine, PD98059 and SB203580).

\section{Matrigel invasion and migration assays}

The effect of test substances on the invasiveness of cells was determined using a modified Boyden chamber technique with Matrigel-coated membranes according to the manufacturer's instructions (BD Biosciences, Oxford, UK). In this assay, tumor cells must overcome a reconstituted basement membrane by a sequential process of proteolytic degradation of the substrate and active migration. In brief, the upper sides of the transwell inserts ( $8 \mu \mathrm{m}$ pore size) were coated with $28.4 \mu \mathrm{g}$ Matrigel (BD Biosciences, Oxford, UK) per 
insert in 24-well plates. Trypsinized and pelleted cells were suspended to a final

concentration of $5 \times 10^{5}$ cells in $500 \mu \mathrm{l}$ serum-free DMEM in each insert and treated with a final concentration of $10 \mu \mathrm{M}$ cannabidiol (except Figure 1B and the data in Table 2) or ethanol vehicle for various incubation times. In Table 2 the half maximal effective concentration $\left(\mathrm{EC}_{50}\right)$ of cannabidiol in eliciting inhibition of Matrigel invasion was used for confirming key invasion experiments. To address the role of cannabinoid-activated receptors, specific antagonists to cannabinoid receptors (AM-251, AM-630) or TRPV1 (capsazepine) were used at a final concentration of $1 \mu \mathrm{M}$. In further experiments, inhibitors of p38 MAPK (SB203580) or p42/44 MAPK activation (PD98059) were used at a final concentration of 10 $\mu \mathrm{M}$. Both receptor antagonists and inhibitors of MAPK pathways were tested vs. DMSO vehicles by adding to the cultures 1 hour prior to starting the incubation with cannabidiol. Cannabidiol was added to the cultures without washing out the antagonists. DMEM containing $10 \%$ FCS was used as a chemoattractant in the companion plate. Following incubation in a humidified incubator at $37^{\circ} \mathrm{C}$ and $5 \% \mathrm{CO}_{2}$ for the indicated times, the noninvading cells on the upper surface of the inserts were removed with a cotton swab, and the viability of the cells on the lower surface was measured by the colorimetric WST-1 test (Roche Diagnostics, Mannheim, Germany). This cell viability test is based on the cleavage of the tetrazolium salt WST-1 (4-[3-(4-lodophenyl)-2-(4-nitrophenyl)-2H-5-tetrazolio]-1.6benzene disulfonate) by mitochondrial succinate-tetrazolium-reductase in metabolically active cells.

For calculation of migration, the viability of cells on the lower side of uncoated invasion chambers was determined by the WST-1 test. Invasion was expressed as the invasion index, which is calculated as the absorbance at $490 \mathrm{~nm}$ of cells that invaded through Matrigelcoated Boyden chambers divided by absorbance of cells that migrated through uncoated control inserts with equal treatment ([invasion/migration] $\times 100 \%)$. For corroboration of the calculated invasion indices in one experiment (Fig. 3C), HeLa cells that had invaded through Matrigel-coated membranes were fixed and stained with Diff-Quick (Medion Diagnostics $\mathrm{GmbH}$, Dügingen, Switzerland) and visualized using a microscope at $200 \times$ magnification. 
To exclude the possibility that the effect of cannabidiol on invasion was an unspecific cytotoxicity-related phenomenon, cell viability was analyzed after cannabidiol exposure. For this purpose, cells were seeded into 48 -well plates at $5 \times 10^{5}$ cells per well to match conditions of invasion assays or at $2.5 \times 10^{5}, 1 \times 10^{5}, 0.5 \times 10^{5}$, and $0.1 \times 10^{5}$ per well for testing lower cell densities in a volume of $500 \mu$ DMEM per well and treated with $10 \mu \mathrm{M}$ cannabidiol or ethanol vehicle for 72 hours. Viability was measured subsequently using the WST-1 test.

The antiinvasive action of cannabidiol was confirmed in another experimental setup. To this end, HeLa cells were seeded at a final concentration of $2.5 \times 10^{6}$ cells in 10-cm dishes in DMEM containing 10\% FCS. After 24 hours cells were washed and treated with cannabidiol or vehicle in serum-free DMEM for an additional 48-hour incubation period. Subsequently, trypsinized and pelleted cells were counted, suspended to a final concentration of $5 \times 10^{5}$ cells in $500 \mu \mathrm{l}$ serum-free DMEM and subjected into each insert without further addition of test substances. Quantification of Matrigel invasion was performed after another 24-hour incubation of HeLa cells in the Boyden chamber.

\section{Quantitative RT-PCR analysis}

HeLa cells were seeded into 48 -well plates at a density of $5 \times 10^{5}$ cells per well. Following incubation of cells with cannabidiol or its vehicle for the indicated times, supernatants were removed and cells were lysed for subsequent RNA isolation using the RNeasy total RNA Kit (Qiagen, Hilden, Germany). $\beta$-Actin- (internal standard) and TIMP-1 mRNA levels were determined by quantitative real-time RT-PCR as described [36]. Primers and probe for human TIMP-1 was an Assay-on-demand ${ }^{\mathrm{TM}}$-product (Applied Biosystems, Darmstadt, Germany).

\section{Western blot analysis}

For determination of TIMP-1, MMP-2 and MMP-9 protein levels in Fig. 2B, cells grown to 
confluence in 48-well-plates were incubated with test substances or vehicles. Afterward, cell culture supernatants were centrifuged at $500 \times \mathrm{g}$ and used for Western Blot analysis. For all other blots, TIMP-1 was determined in supernatants collected from the upper Boyden chambers at the end of the respective invasion experiment. Total protein in the supernatants was measured using the bicinchoninic acid assay (Pierce, Rockford, IL, USA). For Western blot analysis of p38, phospho-p38, p42/44, and phospho-p42/44, cells grown to confluence in 6-well-plates were incubated with cannabidiol or its vehicle for the indicated times. Afterward, cells were washed, harvested, lysed in solubilization buffer (50 mM HEPES pH 7.4, $150 \mathrm{mM}$ $\mathrm{NaCl}, 1 \mathrm{mM}$ EDTA, 1\% (v/v) $\operatorname{Triton}^{\circledR} \mathrm{X}-100,10 \%$ (v/v) glycerol, $1 \mathrm{mM}$ PMSF, $1 \mu \mathrm{g} / \mathrm{ml}$ leupeptin and $10 \mu \mathrm{g} / \mathrm{ml}$ aprotinin), homogenized by sonication, and centrifuged at 10,000 $\mathrm{g}$ for $5 \mathrm{~min}$. Supernatants were used for Western blot analysis. All proteins were separated on a $12 \%$ sodium dodecyl sulfate-polyacrylamide (Applichem, Darmstadt, Germany) gel. Following transfer to nitrocellulose and blocking of the membranes with $5 \%$ milk powder, blots were probed with specific antibodies raised to TIMP-1, MMP-2 and MMP-9 (all antibodies from Oncogene Research Products, San Diego, CA) or p38, phospho-p38, p42/44 and phosphop42/44 (New England BioLabs GmbH, Frankfurt, Germany). Membranes were probed with horseradish peroxidase-conjugated Fab-specific anti-mouse $\lg G$ for detection of TIMP-1 and MMPs (New England BioLabs GmbH, Frankfurt, Germany) or anti-rabbit IgG for analysis of MAPK protein expression (New England BioLabs GmbH, Frankfurt, Germany). Densitometric analysis of TIMP-1 and MMP band intensities was achieved by optical scanning and quantifying using the Quantity One 1-D Analysis Software (Biorad, Muenchen, Germany). Vehicle controls were defined as $100 \%$ for evaluation of changes in protein expression. To ensure that equal amounts of protein in cell culture supernatants used for protein analysis of TIMP-1 and MMPs had been transferred to the membrane, proteins on Western blot membranes were stained with the fluorescent dye Roti-Green (Carl Roth, Karlsruhe, Germany) except for Fig. 2B, were membranes were stained with Ponceau red. To ascertain equal protein loading in Western Blots of supernatants obtained from upper Boyden chambers, a band with a size of about $65 \mathrm{kDa}$ that appeared unregulated is shown as a 
loading control (LC) for protein analysis of supernatants.

\section{SiRNA transfections}

HeLa, C33A, and A549 cells were transfected with siRNA targeting the indicated sequence of TIMP-1 using RNAiFect ${ }^{\oplus}$ as the transfection reagent (Qiagen $\mathrm{GmbH}$, Hilden, Germany) or negative control RNA (Eurogentec, Seraing, Belgium; Cat. No. OR-0030-neg). The target sequence of the TIMP-1 siRNA (Qiagen GmbH, Hilden, Germany) was as follows: 5'tcccatctttttccggacaa-3'. A BLAST search revealed that the sequence selected did not show any homology to other known human genes. Transfections were performed according to the manufactures's instructions. For invasion assays, cells grown to confluence were transfected with $0.25 \mu \mathrm{g} / \mathrm{mL}$ siRNA or non-silencing siRNA as negative control with an equal ratio (w/v) of RNA to transfection reagent for 24 hours in DMEM supplemented with $10 \%$ FCS. Subsequently, cells were treated with trypsin for 3 minutes at $37^{\circ} \mathrm{C}$ in a humidified incubator, centrifuged at $200 \times \mathrm{g}$, resuspended to a final density of $5 \times 10^{5}$ cells in $500 \mu \mathrm{l}$ of serum-free DMEM containing the same amounts of siRNA or non-silencing siRNA to provide constant transfection conditions, and seeded for invasion analysis as described above.

\section{Mouse model of tumor metastasis}

Athymic nude mice (NMRI-nu/nu) were purchased from Charles River GmbH (Sulzfeld, Germany). Mice were given injections of A549 cells $\left(1 \times 10^{6}\right.$ per $100 \mu$ in PBS) through the lateral tail vein (day 1) and, after 24 hours (day 2), were treated with cannabidiol (5 mg/kg body weight) or with vehicle intraperitoneally. Treatment protocols for the evaluation of the antitumorigenic action of cannabidiol in vivo developed by other groups revealed $5 \mathrm{mg}$ cannabidiol per $\mathrm{kg}$ as an appropriate dose for this purpose [17]. In our experiments cannabidiol or vehicle were administered every 72 hour. Mice were sacrificed on day 28 and one lung per animal was evaluated for experimental metastases. To contrast lung nodules, lungs were fixed in Bouin's fluid (picrinic acid $15 \mathrm{ml}$, formol $5 \mathrm{ml}$, acetate $1 \mathrm{ml}$ ), and metastatic nodes were scored under a stereoscopic microscope in an investigator-blinded 
fashion. For histopathological examination lung samples were fixed in $4 \%$ formaline. Paraffin sections were stained with hematoxylin and eosin.

\section{Statistics}

All statistical analyses were undertaken using GraphPad Prism 3.00 (GraphPad Software, San Diego, CA). Results were considered to be statistically significant at $P<0.05$.

To assess the half maximal effective concentration $\left(E C_{50}\right)$ of cannabidiol in eliciting an antiinvasive response, concentration response curves were fitted by a log(agonist) vs. response regression with variable slope. 


\section{Results}

\section{Time-course and concentration-dependency of cannabidiol's inhibitory effect on HeLa cell invasion}

HeLa cells showed a diminished invasion within the first 24 hours of incubation with $10 \mu \mathrm{M}$ cannabidiol that continued to increase over the investigated 72-hour incubation period (Fig. 1A). To exclude an effect based on cell motility, transmigration through uncoated Boyden chambers was evaluated after 48 and 72 hours. As shown in Fig. 1B, cannabidiol did not show a significant inhibitory effect on this parameter.

Moreover, cannabidiol caused a concentration-dependent decrease of invasion that was even significant at concentrations as low as $0.01 \mu \mathrm{M}$ (Fig. 1C). Cellular viability measured under comparable experimental conditions (i.e., 48 well plates with $5 \times 10^{5}$ cells per well) was virtually unaltered in the presence of either cannabidiol concentration tested (Fig. 1C). As recently shown, the phytocannabinoid THC and the hydrolysis-stable endocannabinoid analog $R(+)$-methanandamide revealed a toxic influence on HeLa cells that was dependent on cellular density [23]. A similar pattern was observed for cannabidiol in HeLa cells. As compared with vehicle-treated cells, cell viability was significantly $(P<0.001$, Student's ttest) lowered by a 72-hour treatment with $10 \mu \mathrm{M}$ cannabidiol at cellular densities lower than of $2.5 \times 10^{5}$ cells (Table 1 ).

To confirm the antiinvasive action of cannabidiol in another experimental setup, additional experiments were performed with HeLa cells that were first treated with cannabidiol or vehicle for 48 hours and trypsinized, counted and adjusted to a final cellular density of $0.5 \mathrm{x}$ $10^{5}$ cells per insert thereafter. Quantification of invasiveness was performed after a further incubation of cells in Boyden chambers for another 24 hours. As compared to vehicle [100\% $\pm 17.2 \%$, the invasion index became significantly decreased after pretreatment with cannabidiol at final concentrations of $0.01 \mu \mathrm{M}[42.4 \% \pm 1.5 \% ; P<0.05], 0.1 \mu \mathrm{M}[32.1 \% \pm$ $10.8 \% ; P<0.05], 1 \mu \mathrm{M}[27.8 \% \pm 2 \% ; P<0.01]$, and $10 \mu \mathrm{M}[16.1 \% \pm 4.2 \% ; P<0.01]$. 


\section{Involvement of cannabinoid receptors and TRPV1 in cannabidiol's anti-invasive action}

As previously demonstrated, HeLa, $A 549$ and $C 33 \mathrm{~A}$ cells express $\mathrm{CB}_{1}$ and $\mathrm{CB}_{2}$ receptors as well as TRPV1 [23]. To investigate the role of cannabinoid receptors and TRPV1 in cannabidiol-mediated reduction of HeLa cell invasiveness, the impact of antagonists of $\mathrm{CB}_{1}$ receptor (AM-251), $\mathrm{CB}_{2}$ receptor (AM-630) and TRPV1 (capsazepine) on the cannabidiolreduced invasion was tested. Inhibitors were used at a concentration of $1 \mu \mathrm{M}$ which has been reported to be within the range of concentrations inhibiting $\mathrm{CB}_{1^{-}}, \mathrm{CB}_{2^{-}}$and TRPV1-dependent events [1,37]. As shown in Fig. 1D as well as in Table 2, cannabidiol-induced inhibition of HeLa cell invasion was prevented in the presence of AM-251, AM-630 or the combination of both antagonists that were added to the cultures 1 hour prior to cannabinoid stimulation. Likewise, the TRPV1 antagonist capsazepine fully abolished the anti-invasive action of cannabidiol (Fig. 1D, Table 2). Cannabinoid receptor and TRPV1 antagonists tested without cannabidiol treatment left basal invasiveness virtually unaltered (data not shown).

\section{Effect of cannabidiol on the expression of TIMP-1, MMP-2 and MMP-9}

In experiments addressing the impact of cannabidiol on the expression of TIMP-1, cannabidiol at a concentration of $10 \mu \mathrm{M}$ exhibited a time-dependent induction of TIMP-1 mRNA that became first evident after a 6-hour incubation period (Fig. 2A). In line with the invasion data, cannabidiol increased TIMP-1 protein levels in a concentration-dependent manner (Fig. 2B). Analysis of MMP-2 and MMP-9 revealed no alteration by either concentration of cannabidiol (Fig. 2B).

Impact of cannabinoid receptor- and TRPV1 antagonists on cannabidiol-elicited TIMP-1 induction

Experiments using cannabinoid receptor- and TRPV1 antagonists were performed to determine the receptor targets of cannabidiol involved in the induction of TIMP-1 expression. According to Western blot analyses from cell culture supernatants obtained from the upper Boyden chambers of the respective invasion experiments, cannabidiol-induced TIMP-1 
expression was substantially reduced by antagonists to both $\mathrm{CB}_{1}$ and $\mathrm{CB}_{2}$ receptors (Fig. 2C). Furthermore, cannabidiol-induced TIMP-1 expression was abrogated by the TRPV1 antagonist capsazepine (Fig. 2C).

\section{Effect of TIMP-1 knockdown on the anti-invasive action of cannabidiol}

To further confirm a causal link between cannabidiol-mediated TIMP-1 induction and the accompanied decreased invasion, the expression of TIMP-1 was prevented by transfecting cells with TIMP-1 siRNA. As recently shown by our group, RNA interference with $0.25 \mu \mathrm{g} / \mathrm{ml}$ TIMP-1 siRNA elicits a reduction of cannabinoid-stimulated TIMP-1 expression without altering the basal level of HeLa cell invasiveness [23]. To study the functional impact of cannabidiol-induced TIMP-1 expression on the observed decrease of invasiveness, TIMP-1 knockdown experiments were therefore performed with a final concentration of $0.25 \mu \mathrm{g} / \mathrm{ml}$ TIMP-1 SiRNA.

Referring to Fig. 3A and Table 2, knockdown of TIMP-1 expression led to a significant abrogation of cannabidiol-mediated decrease of invasion, whereas cultures treated with a non-silencing sequence exhibited the same invasion pattern as controls treated with transfection agent only. Monitoring of TIMP-1 secretion into the culture medium of the upper Boyden chamber confirmed a substantial inhibition of cannabidiol-induced TIMP-1 expression in cannabidiol-treated cells additionally transfected with TIMP-1 siRNA (Fig. 3A).

The impact of TIMP-1 siRNA transfection on tumor cell invasion was also confirmed by staining cells invaded through Matrigel-coated membranes after removal of non-invaded cells from the upper surface of the transwell membrane. The pictures in Fig. 3B demonstrate a significantly lower number of cells invaded in the presence of cannabidiol and a reversal of this effect when cells were concomitantly treated with TIMP-1 siRNA. Again, non-interfering sequences elicited an invasive behavior comparable to controls lacking siRNA. 
Effect of blockade of MAPK pathways on cannabidiol's anti-invasive and TIMP-1-inducing action

In further experiments addressing the role of p38 and p42/44 MAPKs in the anti-invasive and TIMP-1-inducing action of cannabidiol, inhibitors of p38 MAPK activity (SB203580, $10 \mu \mathrm{M}$ ) and of p42/44 MAPK activation (PD98059, $10 \mu \mathrm{M}$ ) substantially inhibited both cannabidiol effects (Fig. 4A,B, Table 2). As previously described, SB203580 and PD98059 alone did not modulate baseline TIMP-1 expression and Matrigel invasion of HeLa cells [29].

Additional inhibitor experiments were performed to confirm a causal link between receptor activation and MAPK phosphorylations. As shown in Fig. 4C, cannabidiol induced activation of p38 and p42/44 MAPKs at two early time points following stimulation. According to Fig. $4 \mathrm{D}$, both activations were substantially suppressed by $\mathrm{CB}_{1}$ - and $\mathrm{CB}_{2}$ antagonists as well as by the TRPV1 antagonist.

Role of TIMP-1 in the anti-invasive action of cannabidiol in other tumor cell lines

To exclude that the demonstrated effects are restricted to HeLa cells, experiments were also performed in human lung carcinoma cells (A549, Fig. 5) and in another human cervical carcinoma cell line (C33A, Fig. 6).

Like in HeLa cells, addition of cannabidiol resulted in a profound suppression of invasion through Matrigel-coated transwell plates in A549 (Fig. 5) and C33A cells (Fig. 6). Decreased invasiveness was accompanied by increased TIMP-1 secretion with both events being significantly suppressed by a 1-hour preincubation with antagonists of $\mathrm{CB}_{1}(\mathrm{AM}-251,1 \mu \mathrm{M})$ and $\mathrm{CB}_{2}$ receptors $(\mathrm{AM}-630,1 \mu \mathrm{M})$ alone or in combination and by a TRPV1 antagonist (capsazepine, $1 \mu \mathrm{M}$ ) in A549 (Fig. 5A) and C333A cells (Fig. 6A).

Furthermore, in both cell lines the blockade of p38 or p42/44 pathways led to a significant reconstitution of the cannabidiol-mediated decrease of Matrigel invasion (Fig. 5B and 6B). Like in HeLa cells, TIMP-1 levels in cell culture supernatants of the upper transwell inserts revealed an inverse correlation between invasiveness and TIMP-1 levels (Fig. 5B and 6B). 
To further confirm the causal link between cannabidiol-mediated decrease of invasiveness and elevated TIMP-1 expression, additional RNA interference experiments were performed by targeting TIMP-1 expression with $0.25 \mu \mathrm{g} / \mathrm{ml}$ siRNA and equal concentrations of nonsilencing siRNA in both cell lines after a 72-hour incubation with $10 \mu \mathrm{M}$ cannabidiol. As expected, transfection of A549 and C33A cells with TIMP-1 siRNA led to inhibition of cannabidiol's effects on invasion and corresponding TIMP-1 expression (Fig. 5C and 6C).

Measurement of cellular viability with the WST-1 test revealed no significant toxicity by cannabidiol in A549 cells $(P=0.411)$ and only a weak toxic effect in C33A cells $(P=0.039)$. For viability analysis under conditions comparable to invasion assays, cells were treated with $10 \mu \mathrm{M}$ cannabidiol for 72 hours at a density of $5 \times 10^{5}$ cells per well in a 48 -well plate. The toxic effect became highly significant $(P<0.001$, Student's t-test) when cells of both lines were seeded at cell numbers of $\leq 2.5 \times 10^{5}$ per well (Table 1 ).

\section{Impact of cannabidiol on lung metastases}

We further investigated the impact of cannabidiol on tumor cell metastasis in vivo in a mouse model. For this purpose, A549 cells were injected intravenously through the lateral tail vein of athymic nude mice. According to Fig. 7, the number of lung metastatic nodules was significantly lower in cannabidiol-treated animals as compared to vehicle-treated controls. The decrease of nodules was from an average of 6 nodules in vehicle-treated nude mice to an average of 1 nodule in cannabidiol-treated mice yielding an $84 \%$ inhibition of metastasis. 


\section{Discussion}

An increasing number of data obtained both in vivo and in vitro implicates a possible role for cannabinoids as systemic cancer therapeutics. Although cannabinoids virtually lack side effects of contemporarily used anticancer drugs such as chemotherapeutics-induced emesis and collateral toxicity, cannabinoids' therapeutical use is limited by their psychotropic side effects. Therefore, recent research focussed on non-psychoactive cannabinoid-mimetic compounds such as cannabidiol.

In the present study we identified a cannabinoid receptor- and TRPV1-triggered expression of TIMP-1 as an important mediator of the anti-invasive action of cannabidiol. Cannabidiol was shown to decrease HeLa cell invasion in a time- and concentration-dependent manner. Following a 72-hour incubation period, the decreased invasiveness was significant at a cannabidiol concentration as low as $0.01 \mu \mathrm{M}$ which elicited a $33 \%$ inhibition when compared to vehicle control. Although this effect was less pronounced as compared to an equimolar concentration of THC which yielded a $68 \%$ inhibition of invasion in the same experimental setup [23], the anti-invasive effects of cannabidiol described here occurred in a range of therapeutically relevant concentrations. Accordingly, referring to clinical data on healthy volunteers obtained from studies with Sativex ${ }^{\mathrm{TM}}$ (1:1 ratio of THC and cannabidiol) applied at a 10-mg buccal dose or at self-titrated doses during chronic therapy, cannabidiol peak plasma concentrations of $0.01 \mu \mathrm{M}$ or up to $0.05 \mu \mathrm{M}$ can be achieved in vivo [38]. Moreover, mean cannabidiol plasma levels of $0.036 \mu \mathrm{M}$ were analyzed following a 6-week oral treatment with cannabidiol at doses of $10 \mathrm{mg} / \mathrm{kg} /$ day [39].

With reference to a number of data reporting an anti-invasive effect of TIMP-1 on cancer cell invasion [23,25-31], the present work focussed on the causal link of cannabinoid receptorand TRPV1-mediated activation of MAPK pathways and subsequent TIMP-1 induction as upstream effectors of cannabidiol-mediated suppression of cancer cell invasion. Several lines of evidence presented in this study suggest TIMP-1 induction as a major event underlying cannabidiol's anti-invasive action. First, antagonists of $\mathrm{CB}_{1}$ and $\mathrm{CB}_{2}$ alone or in 
combination as well as an antagonist of TRPV1 caused a significant suppression of both

cannabidiol-induced TIMP-1 expression and activation of the MAPKs p38 and p42/44, and a significant reconstitution of the subsequent suppression of cancer cell invasion. Second, inhibitors of p38 and p42/44 MAPKs pathway that have previously been demonstrated as upstream regulators of TIMP-1 [32,33] elicited a comparable reconstitution of cancer cell invasiveness and inhibition of TIMP-1 induction by cannabidiol. Third, and most convincing, posttranscriptional silencing of cannabidiol-induced TIMP-1 was associated with a removal of its anti-invasive action. A TIMP-1-dependent anti-invasive effect involving activation of cannabinoid receptors, TRPV1 and MAPKs was also proven in another human cervical cancer (C33A) as well as in a human lung cancer cell line (A549), implying that the observed mechanism is of general importance and not restricted to one cell line. Additionally and in line with its anti-invasive action, in vivo studies in thymic-aplastic nude mice revealed a significant inhibition of A549 lung metastasis in cannabidiol-treated animals as compared to vehicle-treated controls. This finding is in agreement with a previous report in which cannabidiol treatment inhibited breast cancer metastasis [17].

An invasion-associated effect that is mainly determined by the ability of cancer cells to secrete matrix-degrading enzymes or to modulate their activity rather than on cellular motility was substantiated by the finding that reduced Matrigel invasion was not associated with a decrease of transmigration through uncoated Boyden chambers after cannabidiol treatment.

To rule out the possibility that decreased invasion by cannabidiol was an unspecific cytotoxicity-related phenomenon, control experiments were also performed to analyse cellular viability which revealed no significant cytotoxicity by cannabidiol under conditions of the experimental set-up of invasion monitoring. In line with recent data obtained with THC and $\mathrm{R}(+)$-methanandamide [23], cannabidiol showed a significant and progressive toxicity only when the density of HeLa, A549 and C33A cells was reduced. Such "inoculum effect" has been described for a number of chemotherapeutic drugs such as tamoxifen [40], doxorubicin and vincristine [41]. Kobayashi et al. [41] demonstrated that at high cell densities, a decreased cellular uptake of chemotherapeutics results in attenuated availability 
of drug molecules at its intracellular binding sites. Finally, the antiinvasive effect of

cannabidiol was confirmed to be comparable in another experimental setting, where HeLa cells treated with cannabidiol or vehicle for 48 hours were readjusted to equal numbers of cells prior to the 24-hour incubation in Matrigel inserts.

There are several issues raised in this study that have to be addressed in future experiments. First, the effect of cannabidiol on TIMP-1 was specific in that the expression of other regulable components of this systems, i.e. MMP-2 and MMP-9, were not influenced by cannabidiol on the level of protein expression. This finding stands in contrast to a recent study from our laboratory reporting a cannabinoid receptor-independent downregulation of MMP-2 by THC and R(+)-methanandamide [23]. Second, in view of the low affinity of cannabidiol to either $\mathrm{CB}_{1}$ and $\mathrm{CB}_{2}$ receptors [10], the involvement of cannabinoid receptors in the anti-invasive and TIMP-1-stimulatory action of cannabidiol was rather surprising. However, in line with our data cannabidiol has been reported to exert several of its effects, including modulation of cytokine release and macrophage chemotaxis [11] as well as antiproliferative [12] and proapoptotic properties [13] in a cannabinoid receptor-dependent manner. One possible explanation for the discrepancy between the low receptor affinity and the apparent involvement of cannabinoid receptors in cannabidiol-mediated effects may be given by cannabidiol's inhibitory action on fatty acid amidohydrolase activity that confers release of anandamide and increased receptor-mediated signalling by this endocannabinoid [16-18]. Additionally, the non-selective cation channel TRPV1 seems to be involved in cannabidiol's anti-invasive effect which is in line with recent findings demonstrating antihyperalgesic [19] and antiproliferative effects [17] of cannabidiol to be mediated via TRPV1. Third, more research is needed to understand the complete mode of action underlying the anti-invasive effect of cannabidiol. Thus, besides TIMP-1, other components such as a modulation of the urokinase plasminogen activator system (Ramer and Hinz, unpublished data) may contribute to the anti-invasive action as well.

Collectively, this is the first report on a cannabinoid receptor- and TRPV1-dependent antiinvasive action of cannabidiol that adresses the aspect of modulation of the matrix 
metalloproteinase system. Induction of TIMP-1 expression and subsequent reduction of invasiveness may play an important role in the anti-tumorigenic activity of cannabidiol whose therapeutical benefits in cancer treatment should be adressed in future clinical trials. 


\section{Acknowledgements}

We thank Ilona Klammfuß and Kathrin Sievert-Küchenmeister (Institute of Experimental

Surgery, University of Rostock, Germany) for their excellent technical assistance. 


\section{References}

[1] Jacobsson SO, Wallin T, Fowler CJ. Inhibition of rat C6 glioma cell proliferation by endogenous and synthetic cannabinoids. Relative involvement of cannabinoid and vanilloid receptors. J Pharmacol Exp Ther 2001; 299:951-9.

[2] Blázquez C, Carracedo A, Barrado L, Real PJ, Fernández-Luna JL, Velasco G et al. Cannabinoid receptors as novel targets for the treatment of melanoma. FASEB J 2006; 20:2633-5

[3] Galve-Roperh I, Sánchez C, Cortés ML, del Pulgar TG, Izquierdo M, Guzmán M. Antitumoral action of cannabinoids: involvement of sustained ceramide accumulation and extracellular signal-regulated kinase activation. Nat Med 2000; 6:313-9.

[4] Hinz B, Ramer R, Eichele K, Weinzierl U, Brune K. Up-regulation of cyclooxygenase-2 expression is involved in $\mathrm{R}(+)$-methanandamide-induced apoptotic death of human neuroglioma cells. Mol Pharmacol 2004; 66:1643-51.

[5] Portella G, Laezza C, Laccetti P, De Petrocellis L, Di Marzo V, Bifulco M. Inhibitory effects of cannabinoid $\mathrm{CB}_{1}$ receptor stimulation on tumor growth and metastatic spreading: actions on signals involved in angiogenesis and metastasis. FASEB J 2003; $17: 1771-3$

[6] Blázquez C, Casanova ML, Planas A, Gómez Del Pulgar T, Villanueva C, FernándezAceñero MJ et al. Inhibition of tumor angiogenesis by cannabinoids. FASEB J 2003; $17: 529-31$

[7] Blázquez C, González-Feria L, Alvarez L, Haro A, Casanova ML, Guzmán M. Cannabinoids inhibit the vascular endothelial growth factor pathway in gliomas. Cancer Res 2004; 64:5617-23.

[8] Pisanti S, Borselli C, Oliviero O, Laezza C, Gazzerro P, Bifulco M. Antiangiogenic activity of the endocannabinoid anandamide: correlation to its tumor-suppressor efficacy. J Cell Physiol 2007; 211:495-503. 
[9] Wade DT, Makela P, Robson P, House H, Bateman C. Do cannabis-based medicinal extracts have general or specific effects on symptoms in multiple sclerosis? A doubleblind, randomized, placebo-controlled study on 160 patients. Mult Scler 2004; 10:43441.

[10] Thomas BF, Gilliam AF, Burch DF, Roche MJ, Seltzman HH. Comparative receptor binding analyses of cannabinoid agonists and antagonists. J Pharmacol Exp Ther $1998 ; 285: 285-92$.

[11] Sacerdote P, Martucci C, Vaccani A, Bariselli F, Panerai AE, Colombo A et al. The nonpsychoactive component of marijuana cannabidiol modulates chemotaxis and IL-10 and IL-12 production of murine macrophages both in vivo and in vitro. J Neuroimmunol $2005 ; 159: 97-105$

[12] Massi P, Vaccani A, Ceruti S, Colombo A, Abbracchio MP, Parolaro D. Antitumor effects of cannabidiol, a nonpsychoactive cannabinoid, on human glioma cell lines. $\mathrm{J}$ Pharmacol Exp Ther 2004; 308:838-45.

[13] McKallip RJ, Lombard C, Fisher M, Martin BR, Ryu S, Grant S et al. Targeting $\mathrm{CB}_{2}$ cannabinoid receptors as a novel therapy to treat malignant lymphoblastic disease. Blood 2002; 100:627-34.

[14] Thomas A, Baillie GL, Phillips AM, Razdan RK, Ross RA, Pertwee RG. Cannabidiol displays unexpectedly high potency as an antagonist of $\mathrm{CB}_{1}$ and $\mathrm{CB}_{2}$ receptor agonists in vitro. Br J Pharmacol 2007; 150:613-23.

[15] Hayakawa K, Mishima K, Hazekawa M, Sano K, Irie K, Orito K et al. Cannabidiol potentiates pharmacological effects of Delta(9)-tetrahydrocannabinol via $\mathrm{CB}_{1}$ receptordependent mechanism. Brain Res 2008; 1188:157-64.

[16] Watanabe K, Kayano Y, Matsunaga T, Yamamoto I, Yoshimura H. Inhibition of anandamide amidase activity in mouse brain microsomes by cannabinoids. Biol Pharm Bull 1996; 19:1109-11. 
[17] Ligresti A, Moriello AS, Starowicz K, Matias I, Pisanti S, De Petrocellis L et al. Antitumor activity of plant cannabinoids with emphasis on the effect of cannabidiol on human breast carcinoma. J Pharmacol Exp Ther 2006; 318:1375-87.

[18] de Filippis D, luvone T, d'Amico A, Esposito G, Steardo L, Herman AG et al. Effect of cannabidiol on sepsis-induced motility disturbances in mice: involvement of $\mathrm{CB}$ receptors and fatty acid amide hydrolase. Neurogastroenterol Motil 2008; 20:919-27.

[19] Costa B, Giagnoni G, Franke C, Trovato AE, Colleoni M. Vanilloid TRPV1 receptor mediates the antihyperalgesic effect of the nonpsychoactive cannabinoid, cannabidiol, in a rat model of acute inflammation. Br J Pharmacol 2004; 143:247-50.

[20] Ryberg E, Larsson N, Sjögren S, Hjorth S, Hermansson NO, Leonova J et al. The orphan receptor GPR55 is a novel cannabinoid receptor. $\mathrm{Br} \mathrm{J}$ Pharmacol 2007; 152:1092-101.

[21] McAllister SD, Christian RT, Horowitz MP, Garcia A, Desprez PY. Cannabidiol as a novel inhibitor of Id-1 gene expression in aggressive breast cancer cells. Mol Cancer Ther 2007; 6:2921-7.

[22] Blázquez C, Salazar M, Carracedo A, Lorente M, Egia A, González-Feria L et al. Cannabinoids inhibit glioma cell invasion by down-regulating matrix metalloproteinase-2 expression. Cancer Res 2008; 68:1945-52.

[23] Ramer R, Hinz B. Inhibition of cancer cell invasion by cannabinoids via increased expression of tissue inhibitor of matrix metalloproteinases-1. J Natl Cancer Inst 2008; 100:59-69.

[24] Curran S, Murray GI. Matrix metalloproteinases: molecular aspects of their roles in tumour invasion and metastasis. Eur J Cancer 2000; 36:1621-30.

[25] Khokha R, Zimmer MJ, Graham CH, Lala PK, Waterhouse P. Suppression of invasion by inducible expression of tissue inhibitor of metalloproteinase-1 (TIMP-1) in B16-F10 melanoma cells. J Natl Cancer Inst 1992; 84:1017-22. 
[26] Cattaneo M, Fontanella E, Canton C, Delia D, Biunno I. SEL1L affects human pancreatic cancer cell cycle and invasiveness through modulation of PTEN and genes related to cell-matrix interactions. Neoplasia 2005; 7:1030-8.

[27] Park MJ, Lee JY, Kwak HJ, Park CM, Lee HC, Woo SH et al. Arsenic trioxide $\left(\mathrm{As}_{2} \mathrm{O}_{3}\right)$ inhibits invasion of HT1080 human fibrosarcoma cells: Role of nuclear factor-kappaB and reactive oxygen species. J Cell Biochem 2005a; 95:955-69.

[28] Park HJ, Lee HJ, Min HY, Chung HJ, Suh ME, Park-Choo HY et al. Inhibitory effects of a benz(f)indole-4,9-dione analog on cancer cell metastasis mediated by the downregulation of matrix metalloproteinase expression in human HT1080 fibrosarcoma cells. Eur J Pharmacol 2005b; 527:31-6.

[29] Ramer R, Eichele K, Hinz B. Upregulation of tissue inhibitor of matrix metalloproteinases- 1 confers the anti-invasive action of cisplatin on human cancer cells. Oncogene 2007; 26:5822-7.

[30] Khokha R, Waterhouse P, Yagel S, Lala PK, Overall CM, Norton G et al. Antisense RNA-induced reduction in murine TIMP levels confers oncogenicity on Swiss 3T3 cells. Science 1989; 24:3947-50.

[31] Chan VY, Chan MW, Leung WK, Leung PS, Sung JJ et al. Intestinal trefoil factor promotes invasion in non-tumorigenic Rat-2 fibroblast cell. Regul Pept 2005; $127: 87$ 94.

[32] Tong L, Smyth D, Kerr C, Catterall J, Richards CD. Mitogen-activated protein kinases Erk1/2 and $\mathrm{p} 38$ are required for maximal regulation of TIMP-1 by oncostatin $\mathrm{M}$ in murine fibroblasts. Cell Signal 2004; 16:1123-32.

[33] Han R, Smith TJ. Induction by IL-1 beta of tissue inhibitor of metalloproteinase-1 in human orbital fibroblasts: modulation of gene promoter activity by IL-4 and IFN-gamma. J Immunol 2005; 174:3072-9.

[34] Sanchez MG, Ruiz-Llorente L, Sanchez AM, Diaz-Laviada I. Activation of 
phosphoinositide 3-kinase/PKB pathway by $\mathrm{CB}_{1}$ and $\mathrm{CB}_{2}$ cannabinoid receptors expressed in prostate PC-3 cells. Involvement in Raf-1 stimulation and NGF induction. Cell Signal 2003; 15:851-9.

[35] Herrera B, Carracedo A, Diez-Zaera M, Guzmán M, Velasco G. p38 MAPK is involved in $\mathrm{CB}_{2}$ receptor-induced apoptosis of human leukaemia cells. FEBS Lett 2005; 579:5084-8.

[36] Hinz B, Rosch S, Ramer R, Tamm ER, Brune K. Latanoprost induces matrix metalloproteinase-1 expression in human nonpigmented ciliary epithelial cells through a cyclooxygenase-2-dependent mechanism. FASEB J 2005; 19:1929-31.

[37] Mukherjee S, Adams M, Whiteaker K, Daza A, Kage K, Cassar S et al. Species comparison and pharmacological characterization of rat and human $\mathrm{CB}_{2}$ cannabinoid receptors. Eur J Pharmacol 2004; 05:1-9.

[38] Sativex Product Monograph; GW Pharma Ltd. Salisbury, Wiltshire U.K. SP4 OJQ Submission Control No: 091289.

[39] Consroe P, Kennedy K, Schram K. Assay of plasma cannabidiol by capillary gas chromatography/ion trap mass spectroscopy following high-dose repeated daily oral administration in humans. Pharmacol Biochem Behav 1991; 40:517-22.

[40] Brandt S, Heller H, Schuster KD, Grote J. Tamoxifen induces suppression of cell viability and apoptosis in the human hepatoblastoma cell line HepG2 via downregulation of telomerase activity. Liver Int 2004; 24:46-54.

[41] Kobayashi H, Takemura $\mathrm{Y}$, Ohnuma T. Relationship between tumor cell density and drug concentration and the cytotoxic effects of doxorubicin or vincristine: mechanism of inoculum effects. Cancer Chemother Pharmacol 1992; 31:6-10. 


\section{Figure legends}

\section{Figure 1}

Influence of cannabidiol (CBD) on HeLa cell invasion. A, Time-dependency of Matrigel invasion of HeLa cells following stimulation of cells with $10 \mu \mathrm{M}$ cannabidiol or vehicle over a 72-hour incubation period. $B$, Migration of HeLa cells through uncoated Boyden chambers after a 48- and 72-hour stimulation with $10 \mu \mathrm{M}$ cannabidiol or vehicle. $C$, Concentrationdependency of cannabidiol's anti-invasive action (black bars) and its impact on cell viability (open bars) after a 72-hour incubation period. $D$, Effect of a 1-hour pretreatment with AM-251 (AM1; $\mathrm{CB}_{1}$ antagonist; $1 \mu \mathrm{M}$ ), AM-630 (AM2; $\mathrm{CB}_{2}$ antagonist; $\left.1 \mu \mathrm{M}\right)$ and capsazepine (capsa; TRPV1 antagonist; $1 \mu \mathrm{M})$ on the anti-invasive action of cannabidiol (10 $\mu \mathrm{M})$ after a 72 -hour incubation. Values are means \pm SEM of $n=4(A, B), n=3-4(C)$, and $n=7-8$ (D) experiments. ${ }^{\star} P<0.05 ;{ }^{* *} P<0.01 ;{ }^{* \star} P<0.001$, vs. corresponding vehicle control; ${ }^{\# \#} P<$ 0.001 vs. cannabidiol-treated cells, Student's t-test.

\section{Figure 2}

Impact of cannabidiol (CBD) on TIMP-1 expression. A, Time-course of TIMP-1 mRNA normalized to ß-actin. Cells were incubated with $10 \mu \mathrm{M}$ cannabidiol or its vehicle over a 48hour incubation period. $B$, Concentration-dependent effect of cannabidiol $(0.01-10 \mu \mathrm{M})$ or its vehicle on TIMP-1, MMP-2 and MMP-9 protein levels following a 72-hour incubation of cells. C, Influence of a 1-hour preincubation with AM-251 (AM1; $\mathrm{CB}_{1}$ antagonist; $\left.1 \mu \mathrm{M}\right), \mathrm{AM}-630$ (AM2; $\mathrm{CB}_{2}$ antagonist; $1 \mu \mathrm{M}$ ) and capsazepine (capsa; TRPV1 antagonist; $1 \mu \mathrm{M}$ ) on cannabidiol-mediated TIMP-1 induction. $D$, Influence of receptor antagonists on TIMP-1 expression without cannabidiol treatment. mRNA data $(A)$ are means \pm SEM of $n=3$ experiments. ${ }^{*} P<0.05 ;{ }^{* *} P<0.01$, vs. corresponding vehicle control (Student's t-test). Values above selected blots are means \pm SEM obtained from densitometric analysis of $n=4$ $(B, C)$ or $n=3(D)$ blots and represent percent control in comparison with vehicle-treated cells $(100 \%)$ in the absence of test substance. Protein staining of supernatants is shown as 
loading control (LC).

\section{Figure 3}

Role of TIMP-1 in cannabidiol's (CBD) effect on HeLa cell invasion. $A$, Effect of TIMP-1 siRNA $(0.25 \mu \mathrm{g} / \mathrm{mL})$ on cannabidiol's action on cell invasion and TIMP-1 protein expression. HeLa cells were transfected with TIMP-1 siRNA at a final concentration of $0.25 \mu \mathrm{g} / \mathrm{ml}$ siRNA (si) or with non-silencing siRNA (nonsi) for 24 hours. Subsequently, cells were placed into invasion chambers, retransfected with the indicated type of siRNA or suspension buffer to provide constant knockdown conditions and incubated with $10 \mu \mathrm{M}$ cannabidiol or vehicle for a further 72 hours. Protein staining of supernatants is shown as loading control (LC). B, Microscopy of HeLa cells from different treatment groups that invaded through Matrigelcoated membranes. Cells were stained with Diff-Quick $^{\circledR}$ (Medion Diagnostics $\mathrm{GmbH}$, Büdingen, $\mathrm{CH}$ ) and documented under a $200 \times$ magnification. Percent control (A) represents comparison with vehicle-treated cells (100\%) in the absence of test substance. Values are means \pm SEM of $n=4$ experiments. ${ }^{* * *} P<0.001$, vs. corresponding vehicle control; ${ }^{\# \#} P<$ 0.001 , vs. cannabidiol (Student's t-test).

\section{Figure 4}

Role of p38 and p42/44 mitogen-activated protein kinase (MAPK) pathways in the effects of cannabidiol (CBD) on HeLa cell invasion and TIMP-1 expression. A, Effect of a 1-hour pretreatment with $10 \mu \mathrm{M}$ SB203580 (SB; inhibitor of p38 MAPK activity) and $10 \mu \mathrm{M}$ PD98059 (PD; inhibitor of p42/44 MAPK activation) on the anti-invasive action of cannabidiol (10 $\mu \mathrm{M})$ after a 72-hour incubation period. B, Effect of the indicated treatment on TIMP-1 protein levels after a 72-hour incubation period. Percent control represents comparison with vehicletreated cells $(100 \%)$ in the absence of test substance. Values are means \pm SEM of $n=3-4$ experiments $(\mathrm{A}),{ }^{* * *} P<0.001$, vs. corresponding vehicle control; ${ }^{\# \#} P<0.001$, vs. cannabidiol (Student's t-test). Values above the representative blot are means \pm SEM obtained from densitometric analysis of $n=7$ blots (B) and represent percent control in 
comparison with vehicle-treated cells $(100 \%)$ in the absence of test substance. Protein

staining of supernatants is shown as loading control (LC). C, Effect of cannabidiol on activation of p38 and p42/44 MAPK after $0.25-12$ hours. $D$, Effect of a 1-hour pretreatment with AM-251 (AM1; $1 \mu \mathrm{M})$, AM-630 (AM2; $1 \mu \mathrm{M})$, and capsazepine (Capsa; $1 \mu \mathrm{M})$ on phosphorylation of p38 and p42/44 MAPKs after a 2-hour incubation with $10 \mu \mathrm{M}$ cannabidiol. To analyze MAPK phosphorylations, immunoblots were probed with antibodies directed against the phosphorylated form of p38 or p42/44. Equal loading of lysates was ensured by probing membranes with antibodies against the nonphosphorylated forms of p38 and p42/44 MAPKs.

\section{Figure 5}

Involvement of cannabinoid receptors, TRPV1, p38 and p42/44 MAPKs in the TIMP-1dependent anti-invasive action of cannabidiol (CBD) on A549 cells. A, Effect of a 1-hour pretreatment of cells with $\mathrm{AM}-251\left(\mathrm{AM} 1 ; \mathrm{CB}_{1}\right.$ antagonist; $\left.1 \mu \mathrm{M}\right), \mathrm{AM}-630\left(\mathrm{AM} 2 ; \mathrm{CB}_{2}\right.$ antagonist; $1 \mu \mathrm{M}$ ) and capsazepine (capsa; TRPV1 antagonist; $1 \mu \mathrm{M}$ ) on the anti-invasive (A, upper panel) and TIMP-1-inducing action of $10 \mu \mathrm{M}$ cannabidiol (A, lower panel). B, Effect of a 1-hour pretreatment with $10 \mu \mathrm{M}$ SB203580 (SB; inhibitor of p38 MAPK activity) and $10 \mu \mathrm{M}$ PD98059 (PD; inhibitor of p42/44 MAPK activation) on the anti-invasive action of $10 \mu \mathrm{M}$ cannabidiol (B, upper panel) and on TIMP-1 protein levels (B, lower panel) after a 72-hour incubation period. $C$, Effect of TIMP-1 siRNA $(0.25 \mu \mathrm{g} / \mathrm{mL})$ on cannabidiol's action on A549 cell invasion (C, upper panel) and TIMP-1 expression (C, lower panel). Percent control represents comparison with vehicle-treated cells $(100 \%)$ in the absence of test substance of $n=3-4(A)$, and $n=4(B, C)$ experiments. ${ }^{* *} P<0.001$, vs. corresponding vehicle control; \#\# $P<0.001 ;{ }^{\#} P<0.01$, vs. cannabidiol (Student's t-test). Values above the representative TIMP-1 blots are means \pm SEM obtained from densitometric analysis of $n=4(A)$ or $n=5$ (B) blots and represent percent control in comparison with vehicle-treated cells $(100 \%)$ in the absence of test substance. Protein staining of supernatants is shown as loading control (LC). 


\section{Figure 6}

Involvement of cannabinoid receptors, TRPV1, p38 and p42/44 MAPKs in the TIMP-1dependent anti-invasive action of cannabidiol (CBD) on C33A cells. A, Effect of a 1-hour pretreatment of cells with $\mathrm{AM}-251$ (AM1; $\mathrm{CB}_{1}$ antagonist; $\left.1 \mu \mathrm{M}\right)$, AM-630 (AM2; $\mathrm{CB}_{2}$ antagonist; $1 \mu \mathrm{M}$ ) and capsazepine (capsa; TRPV1 antagonist; $1 \mu \mathrm{M}$ ) on the anti-invasive (A, upper panel) and TIMP-1-inducing action of $10 \mu \mathrm{M}$ cannabidiol (A, lower panel). B, Effect of a 1-hour pretreatment with $10 \mu \mathrm{M}$ SB203580 (SB; inhibitor of p38 MAPK activity) and PD98059 (PD; inhibitor of p42/44 MAPK activation) on the anti-invasive action of $10 \mu \mathrm{M}$ cannabidiol (B, upper panel) and on TIMP-1 protein levels (B, lower panel) after a 72-hour incubation period. C, Effect of TIMP-1 siRNA $(0.25 \mu \mathrm{g} / \mathrm{mL}$ ) on cannabidiol's action on C33A cell invasion (C, upper panel) and TIMP-1 expression (C, lower panel). Percent control represents comparison with vehicle-treated cells $(100 \%)$ in the absence of test substance of $n=4$ experiments. ${ }^{* * *} P<0.001$; vs. corresponding vehicle control; ${ }^{\# \#} P<0.001$, vs. cannabidiol (Student's t-test). Values above the representative TIMP-1 blots are means \pm SEM obtained from densitometric analysis of $n=5$ (A) or $n=3$ (B) blots and represent percent control in comparison with vehicle-treated cells $(100 \%)$ in the absence of test substance. Protein staining of supernatants is shown as loading control (LC).

\section{Figure 7}

In vivo action of cannabidiol (CBD) on tumor metastasis. A549 cells were injected intravenously in athymic nude mice. Mice were given cannabidiol ( $5 \mathrm{mg} / \mathrm{kg}$ body weight) all 72 hours for 28 days starting 24 hours after injection of the cells. At the end of the experiment, the animals were sacrificed and one lung per animal was evaluated for metastatic lesions. A. Left panel: Number of metastatic nodules in vehicle- and cannabidioltreated mice. Data are means \pm SEM obtained from $n=5$ mice per group. Right panel: Illustration of metastatic lesions in murine lungs from different experimental groups as indicated above. B. Illustration of metastatic lesions in hematoxylin and eosin stained paraffine sections in murine lungs from vehicle- and cannabidiol-treated mice. 


\section{Tables}

\section{Table 1}

Influence of cellular density on the viability of cannabidiol (CBD)-treated HeLa, A549 and C33A cells. Cells were seeded with the indicated number of cells per well of a 48-well plate in serum free DMEM and treated with $10 \mu \mathrm{M}$ cannabidiol or vehicle, respectively. After a $72-$ hour incubation time, cellular viability was measured by WST-1. Values are means \pm SEM of $\mathrm{n}=4$ experiments vs. corresponding vehicle control. ${ }^{*} P<0.05$, ${ }^{* * *} P<0.001$, vs. corresponding vehicle control (Student's t-test).

\begin{tabular}{|c|c|c|c|c|c|c|}
\hline \multirow{3}{*}{$\begin{array}{l}\text { Seeded cell } \\
\text { number }\end{array}$} & \multicolumn{6}{|c|}{ Cellular viability (\%) } \\
\hline & \multicolumn{2}{|r|}{ HeLa } & \multicolumn{2}{|r|}{ A549 } & \multicolumn{2}{|r|}{ C33A } \\
\hline & Vehicle & CBD & Vehicle & CBD & Vehicle & CBD \\
\hline $5.0 \times 10^{5}$ & $100 \pm 8.9$ & $98.3 \pm 7.6$ & $100 \pm 8.4$ & $90.7 \pm 6.3$ & $100 \pm 5.2$ & $82.8 \pm 4.1^{*}$ \\
\hline $2.5 \times 10^{5}$ & $100 \pm 2.3$ & $62.5 \pm 2.6^{* * *}$ & $100 \pm 4.1$ & $54.8 \pm 1.1^{\star \star \star}$ & $100 \pm 6.0$ & $56.2 \pm 3.6^{\star * \star}$ \\
\hline $1.0 \times 10^{5}$ & $100 \pm 1.1$ & $2.0 \pm 0.2^{* \star *}$ & $100 \pm 3.3$ & $1.5+0.6^{\star \star \star}$ & $100 \pm 8.4$ & $12.1 \pm 2.6^{* * *}$ \\
\hline $0.5 \times 10^{5}$ & $100 \pm 6.9$ & $1.8 \pm 0.1^{\star \star \star}$ & $100 \pm 1.4$ & $1.5+0.7^{\star \star \star}$ & $100 \pm 6.2$ & $11.4+0.8^{* \star *}$ \\
\hline $0.1 \times 10^{5}$ & $100 \pm 4.2$ & $3.3 \pm 0.2^{* \star *}$ & $100 \pm 17.5$ & $1.0 \pm 0.8^{\star * \star}$ & $100 \pm 1.3$ & $10.6 \pm 4.4^{* * *}$ \\
\hline
\end{tabular}




\section{Table 2}

Involvement of cannabinoid receptors, TRPV1, p38 and p42/44 MAPKs and TIMP-1 in the anti-invasive action of $0.025 \mu \mathrm{M}$ cannabidiol (CBD) on HeLa cells. Effect of a 1-hour pretreatment of cells with $\mathrm{AM}-251\left(\mathrm{CB}_{1}\right.$ antagonist; $\left.1 \mu \mathrm{M}\right), \mathrm{AM}-630\left(\mathrm{CB}_{2}\right.$ antagonist; $\left.1 \mu \mathrm{M}\right)$ and capsazepine (TRPV1 antagonist; $1 \mu \mathrm{M}$ ) on the anti-invasive action of $0.025 \mu \mathrm{M}$ cannabidiol (upper set). Effect of a 1-hour pretreatment with $10 \mu \mathrm{M} \mathrm{SB203580} \mathrm{(inhibitor} \mathrm{of}$ p38 MAPK activity) and PD98059 (inhibitor of p42/44 MAPK activation) on the anti-invasive action of $0.025 \mu \mathrm{M}$ cannabidiol (middle set), and effect of TIMP-1 siRNA $(0.25 \mu \mathrm{g} / \mathrm{mL})$ or nonsilencing siRNA $(0.25 \mu \mathrm{g} / \mathrm{mL})$ on the antiinvasive action of $0.025 \mu \mathrm{M}$ cannabidiol (lower set). Cells were incubated with cannabidiol for 72 hours. Percent control represents comparison with vehicle-treated cells (100\%) in the absence of test substance of $n=4$ experiments. ${ }^{* * *} P$ $<0.001$; vs. corresponding vehicle control; ${ }^{\# \#} P<0.001$, vs. cannabidiol (Student's t-test).

\begin{tabular}{|l|c|}
\hline & Invasion Index (\%) \\
\hline Vehicle & $100 \pm 5.8$ \\
\hline CBD & $43.7 \pm 2.1^{* * *}$ \\
\hline CBD + AM-251 $(1 \mu \mathrm{M})$ & $87.8 \pm 0.9^{\# \# \#}$ \\
\hline CBD + AM-630 $(1 \mu \mathrm{M})$ & $86.7 \pm 5.3^{\# \#}$ \\
\hline CBD + AM-251 $(1 \mu \mathrm{M})+\mathrm{AM}-630(1 \mu \mathrm{M})$ & $99.3 \pm 6.6^{\# \# \#}$ \\
\hline CBD + Capsazepine $(1 \mu \mathrm{M})$ & $92.3 \pm 4.9^{\# \# \#}$ \\
\hline & $100 \pm 7.4$ \\
\hline Vehicle & $42.8 \pm 1.3^{* * *}$ \\
\hline CBD & $77.9 \pm 1.3^{\# \# \#}$ \\
\hline CBD + SB203580 $(10 \mu \mathrm{M})$ & $115.4 \pm 3.5^{\# \# \#}$ \\
\hline CBD + PD98059 $(10 \mu \mathrm{M})$ & \\
\hline & $100 \pm 12.6$ \\
\hline Vehicle & $45.2 \pm 1.4^{\text {*** }}$ \\
\hline CBD & $90.6 \pm 3.6^{\# \# \#}$ \\
\hline CBD + TIMP-1 siRNA & $93.2 \pm 6.2$ \\
\hline TIMP-1 siRNA & $45.2 \pm 2.5$ \\
\hline CBD + non-silencing siRNA & $103.5 \pm 2.3$ \\
\hline Non-silencing siRNA & \\
\hline
\end{tabular}


A

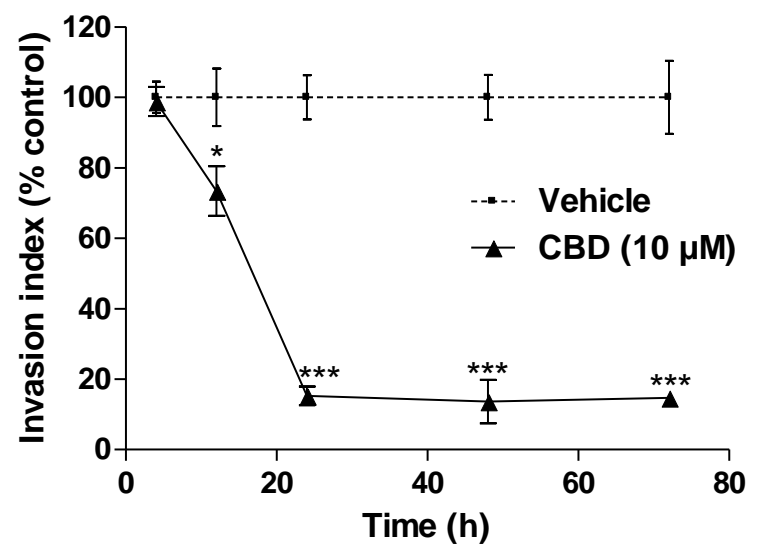

C

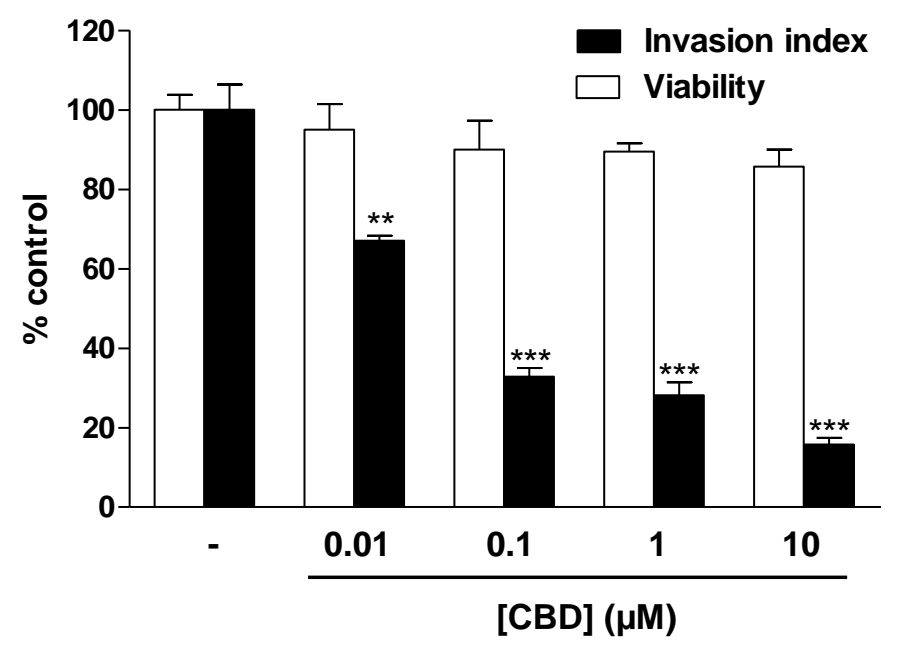

B

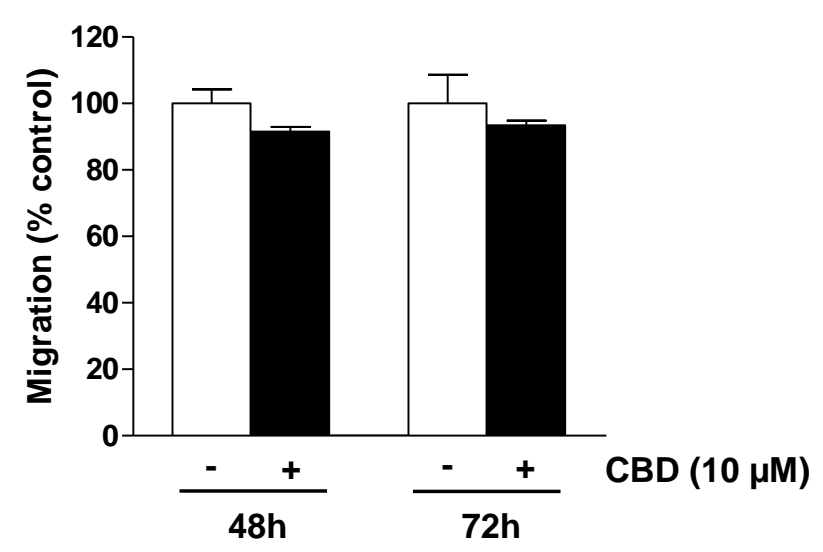

D

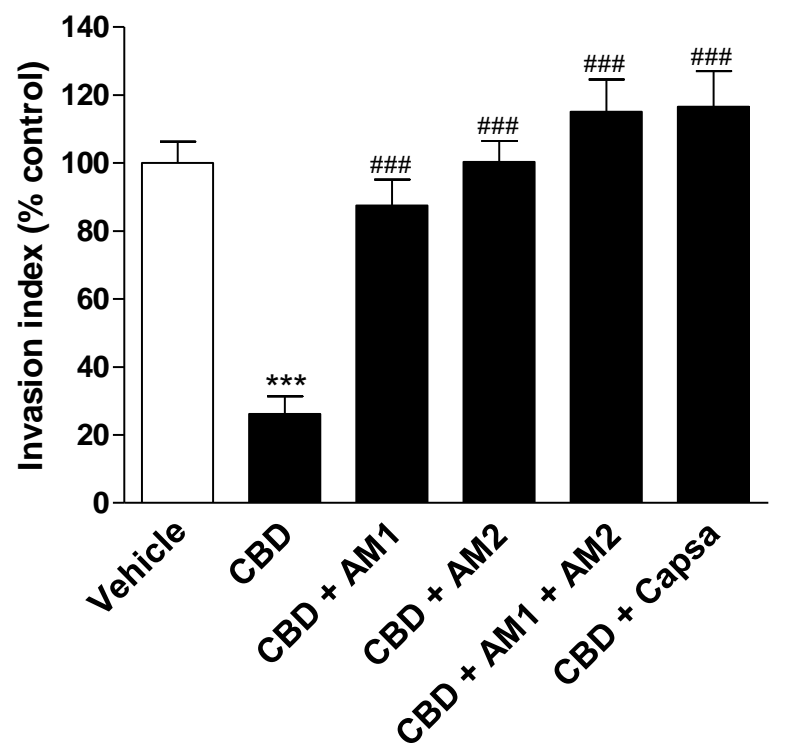


A

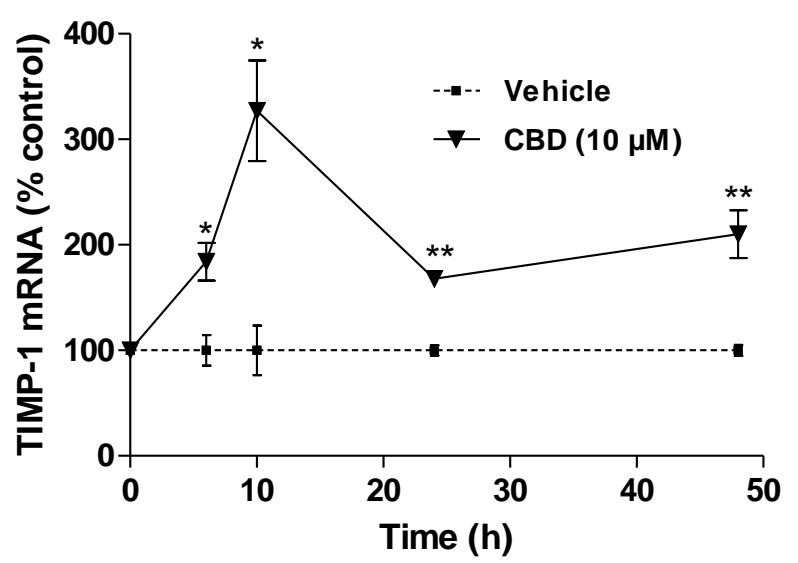

B

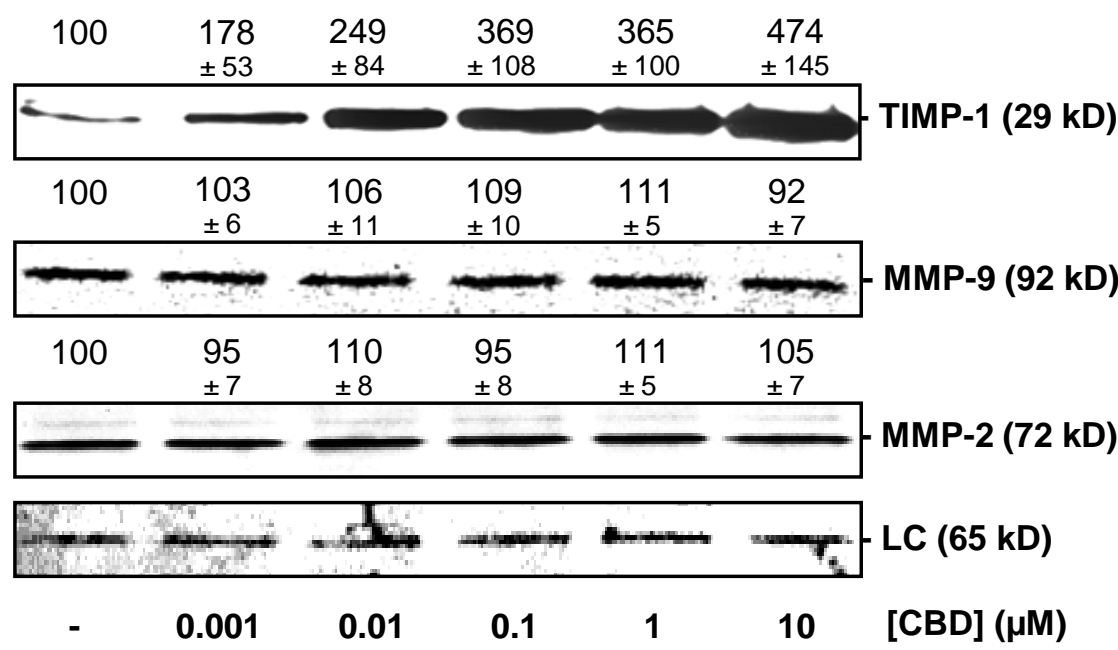

C

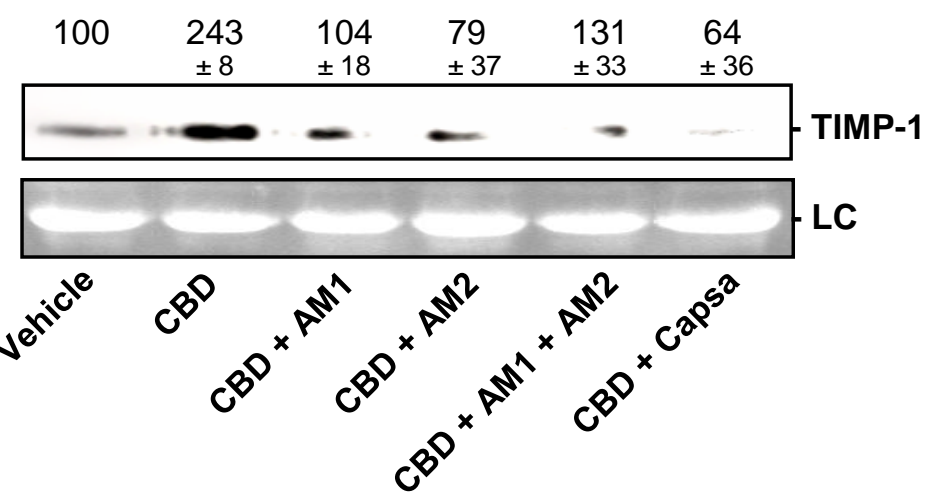

D

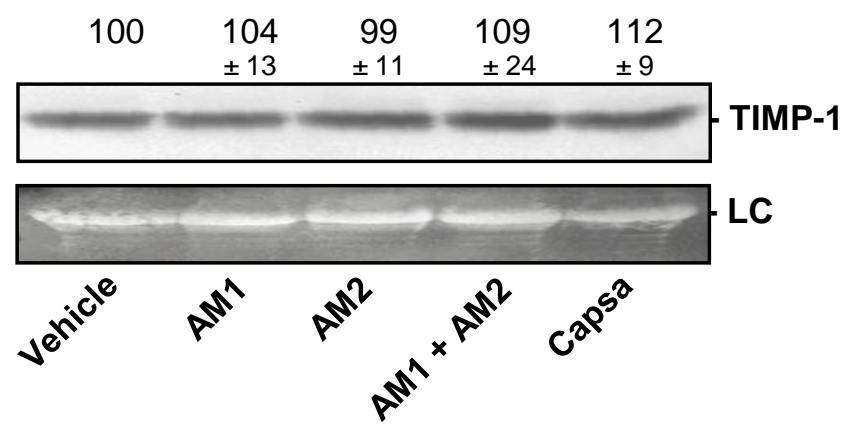

Fig. 2 
A

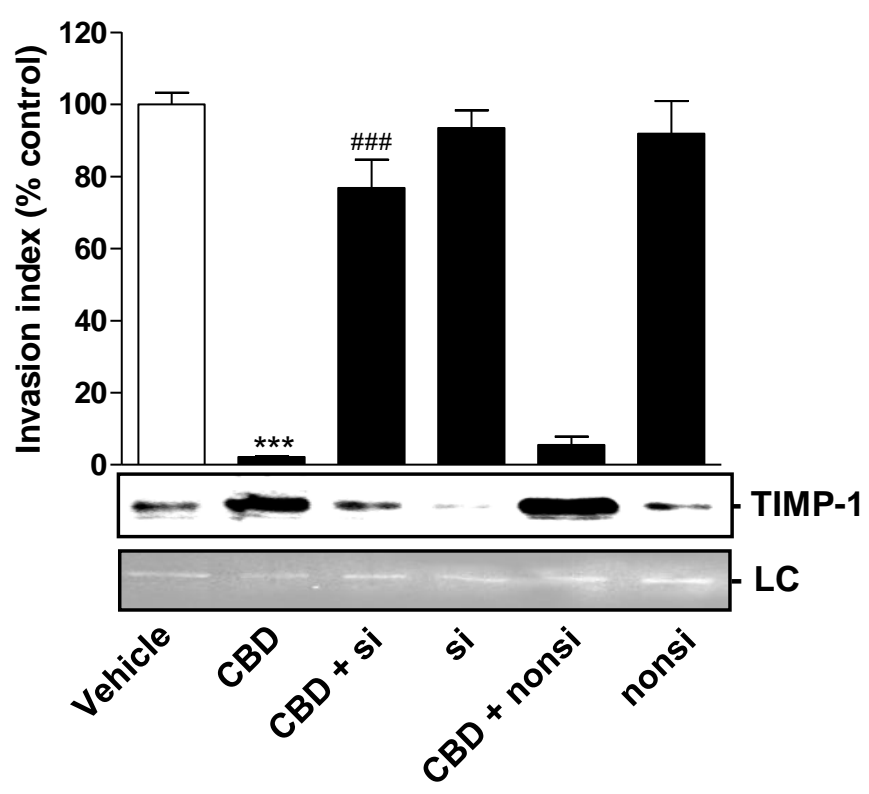

B

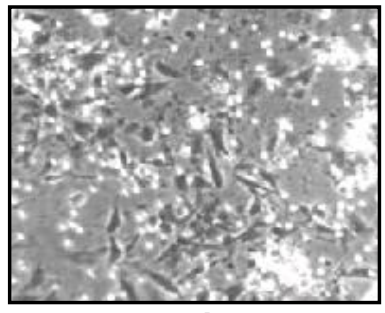

Vehicle

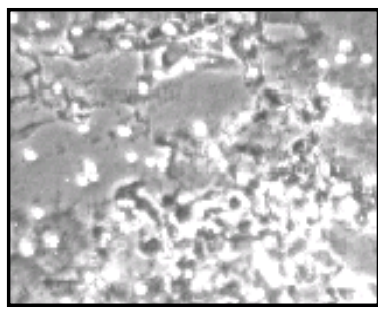

si

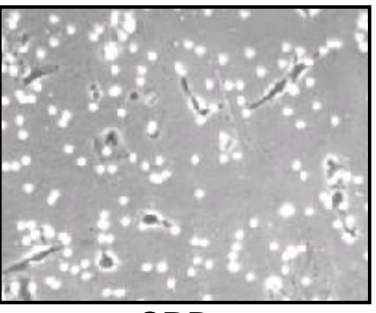

CBD

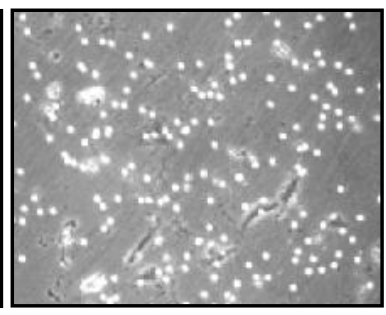

CBD + nonsi
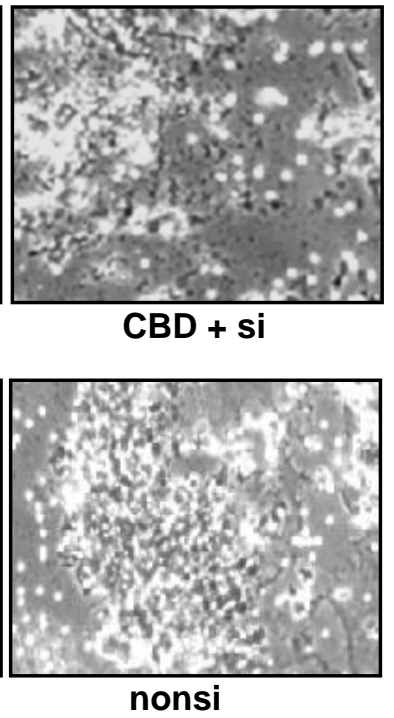

Fig. 3 


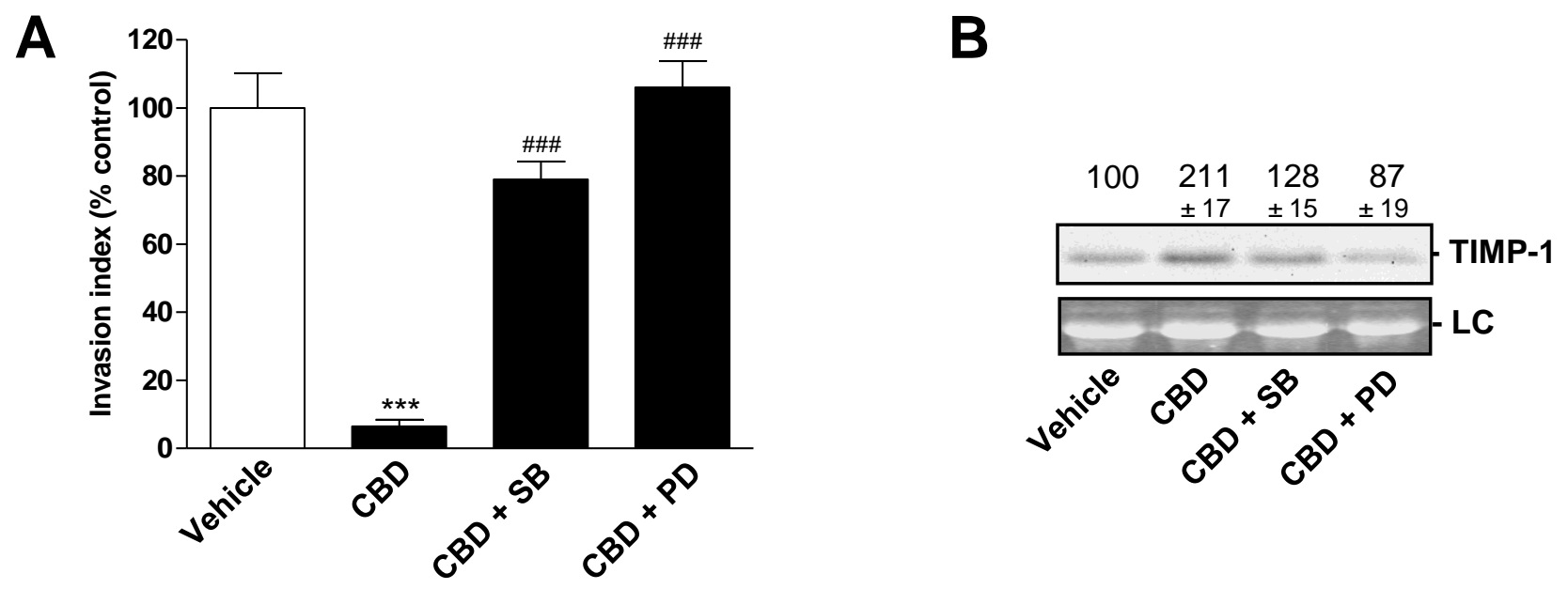

C

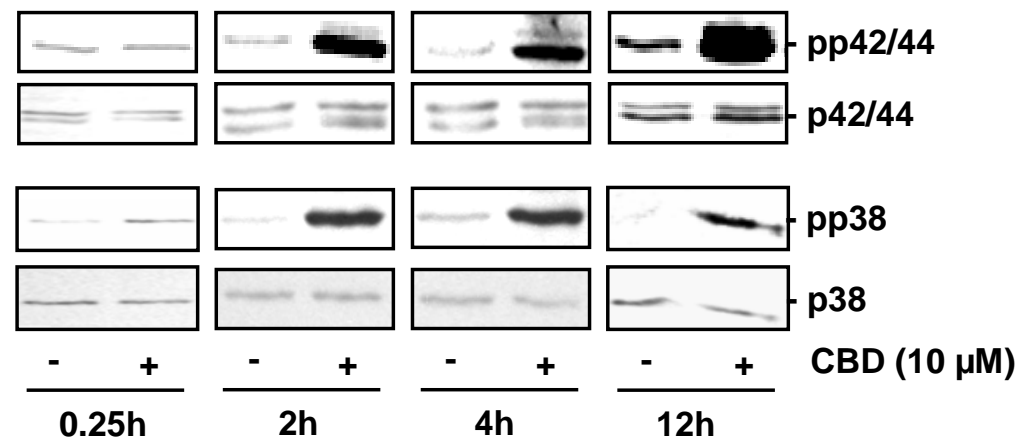

D

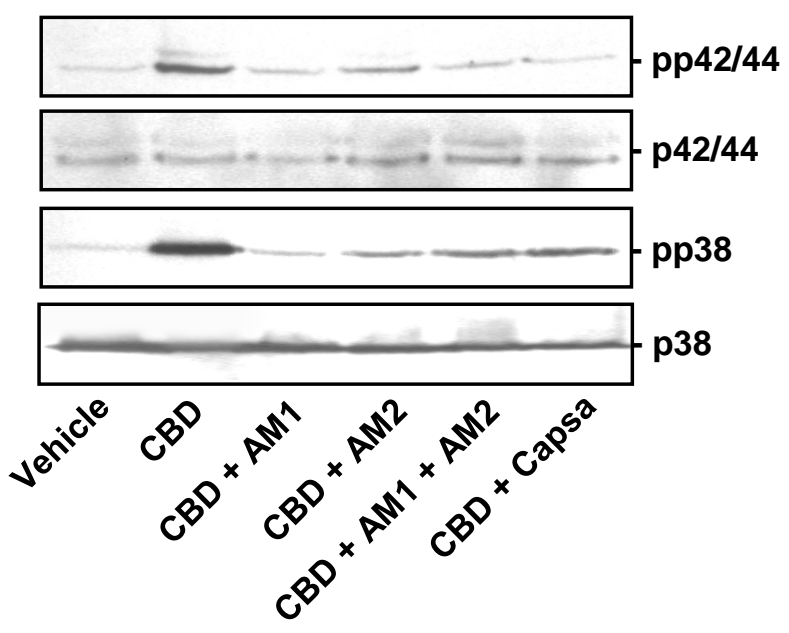

Fig. 4 
A
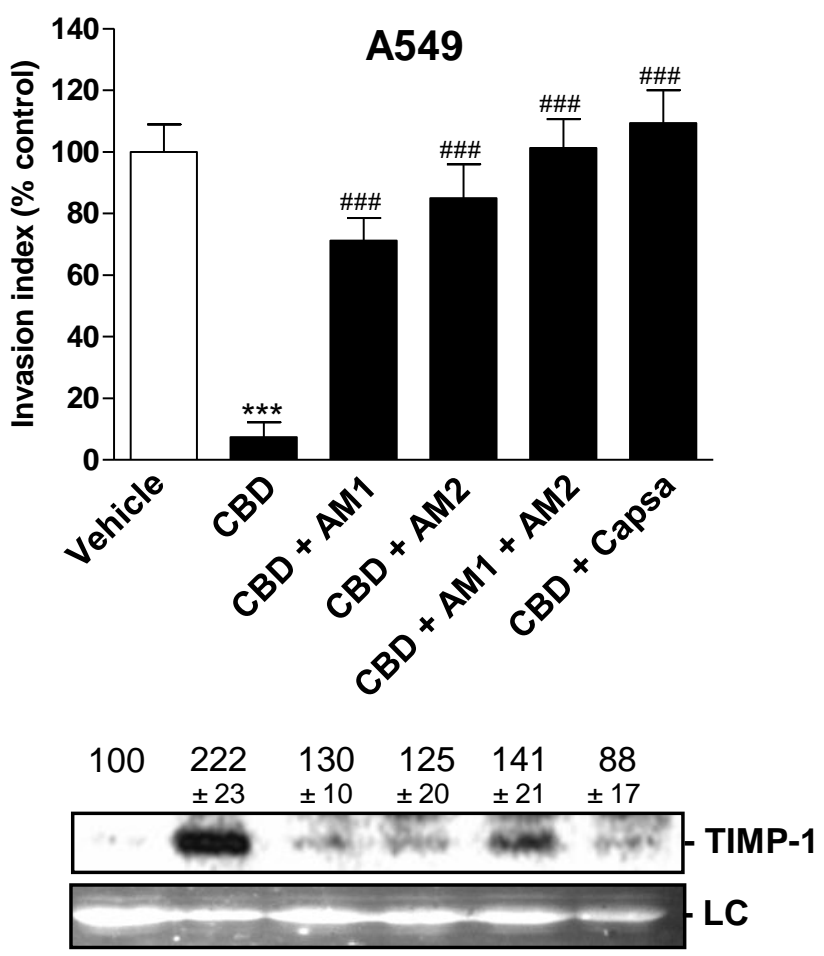

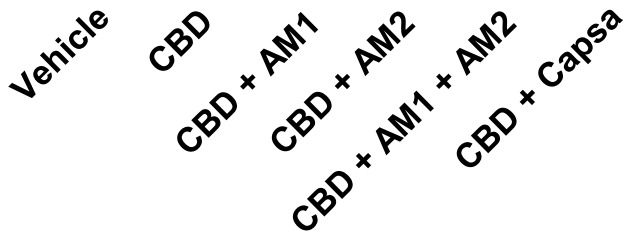

B
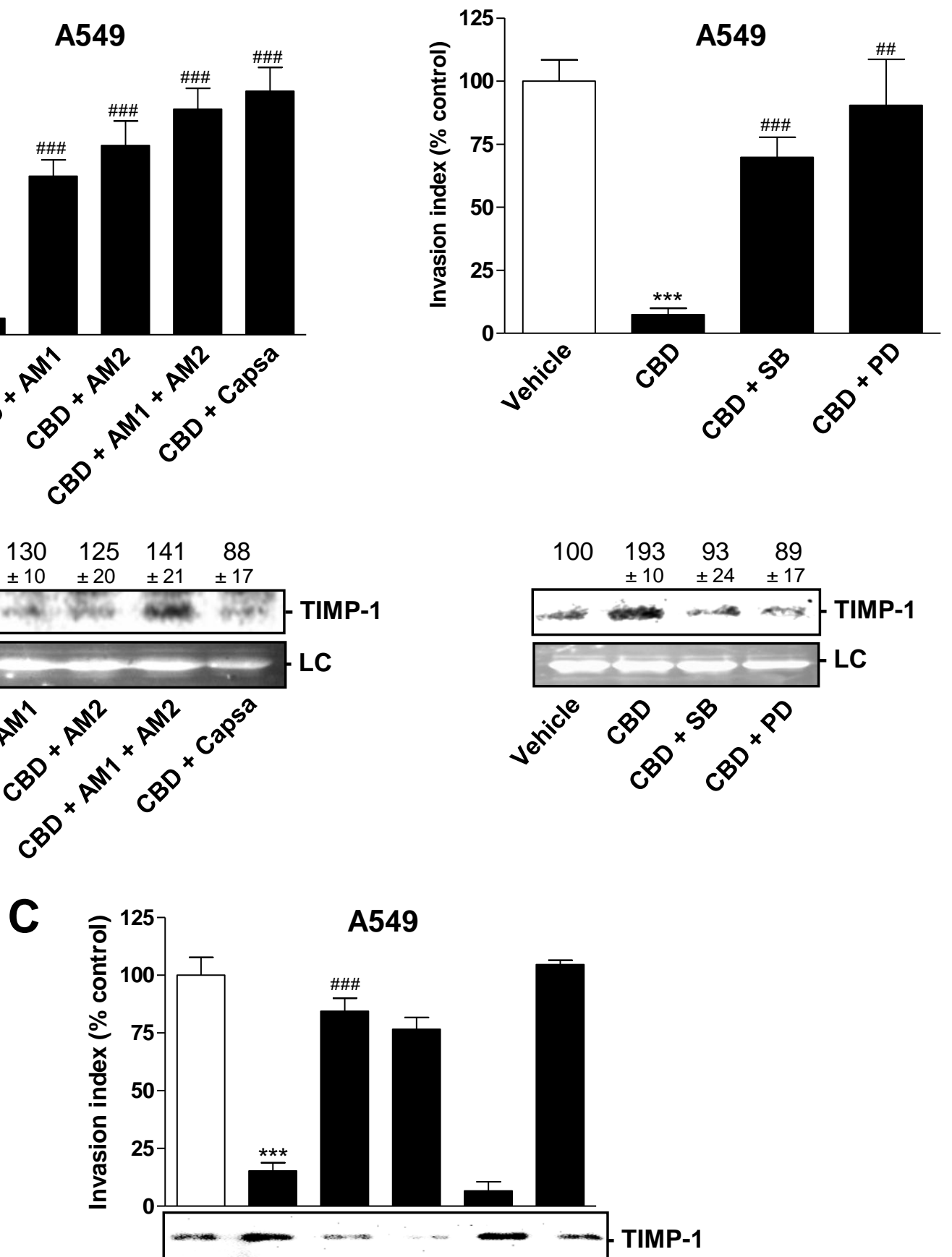

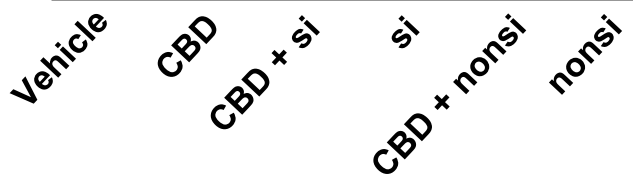

Fig. 5 
A
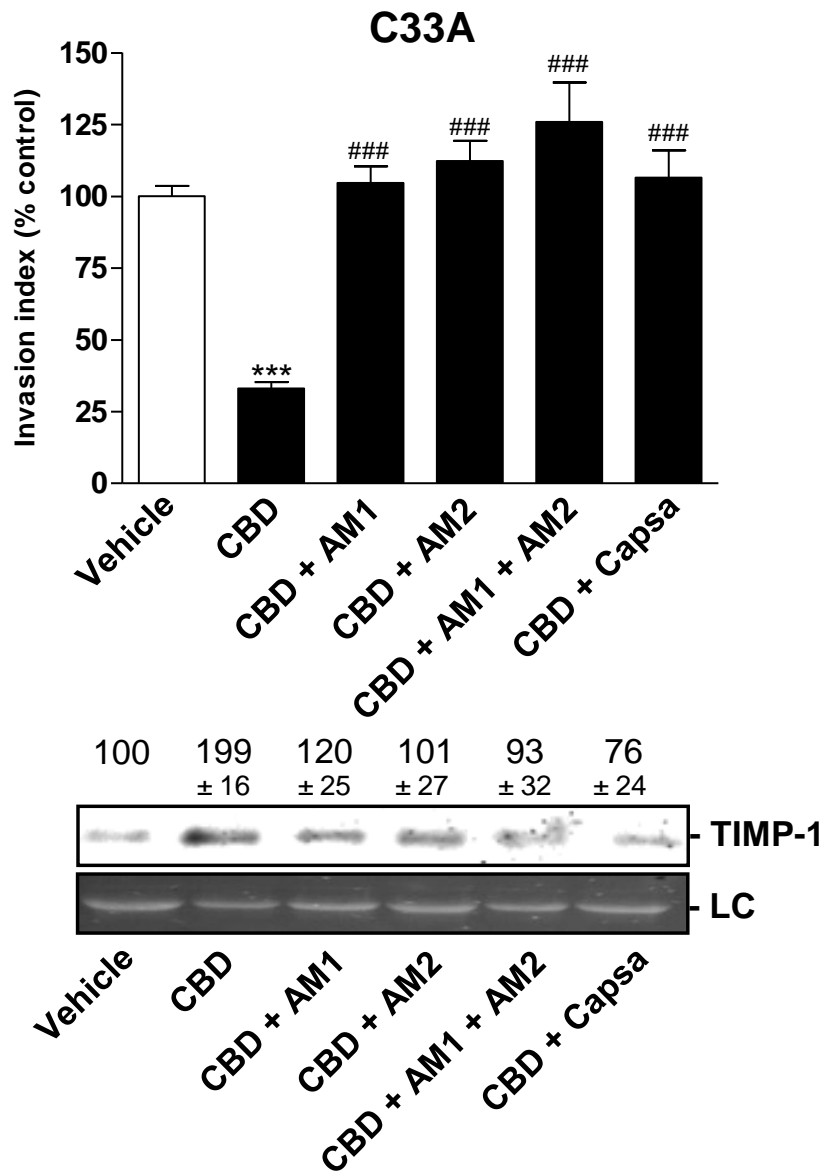

B
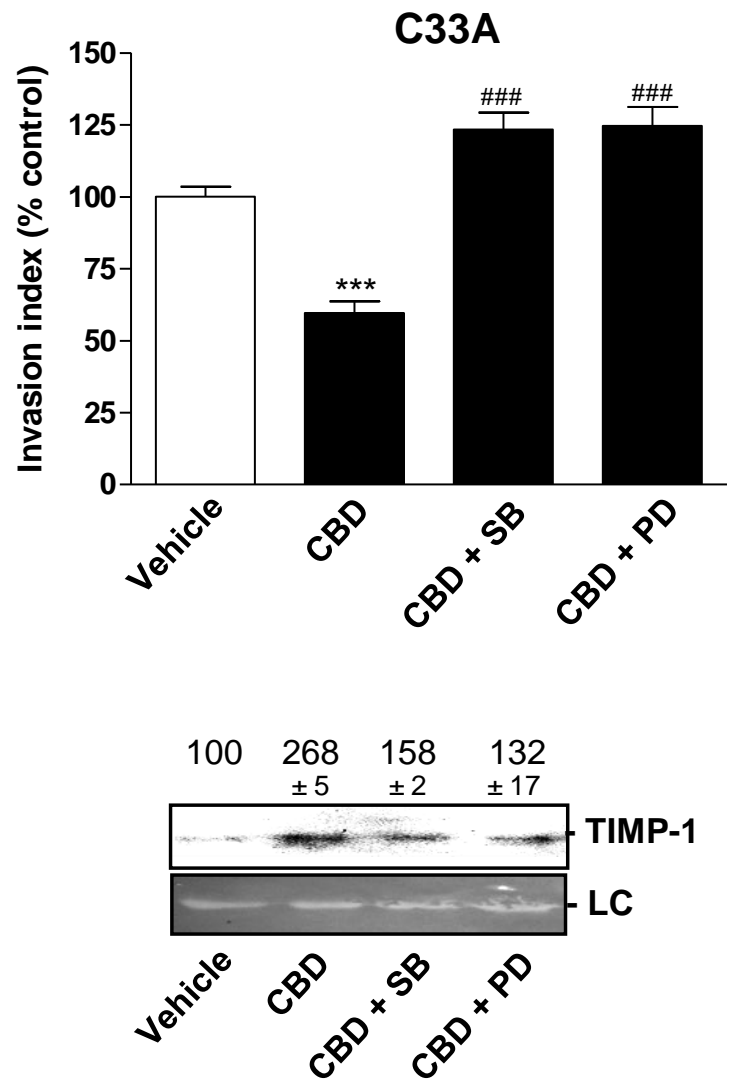

C

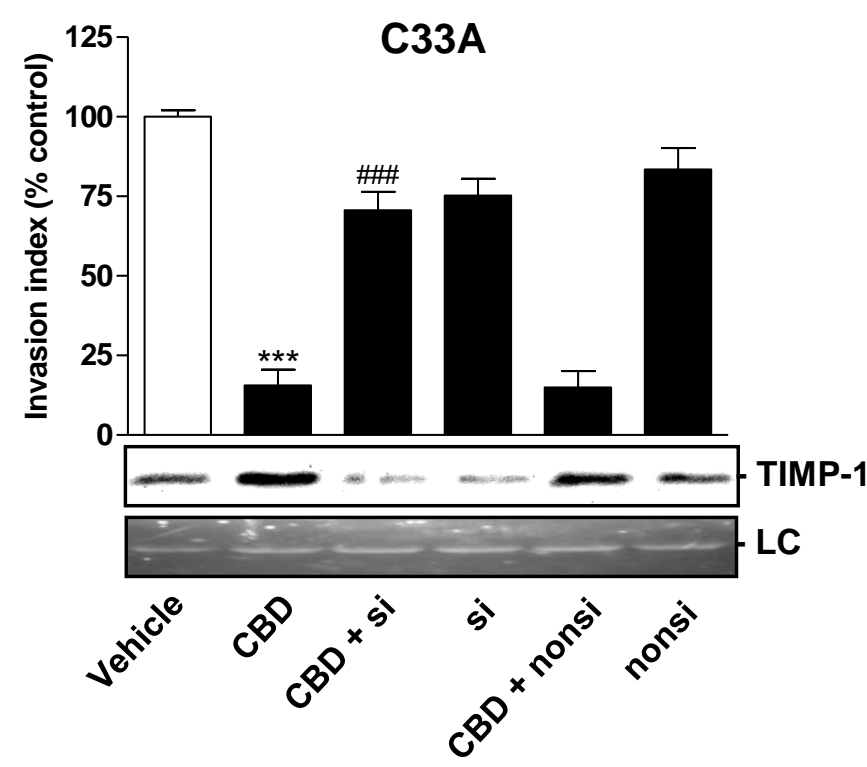

Fig. 6 
A

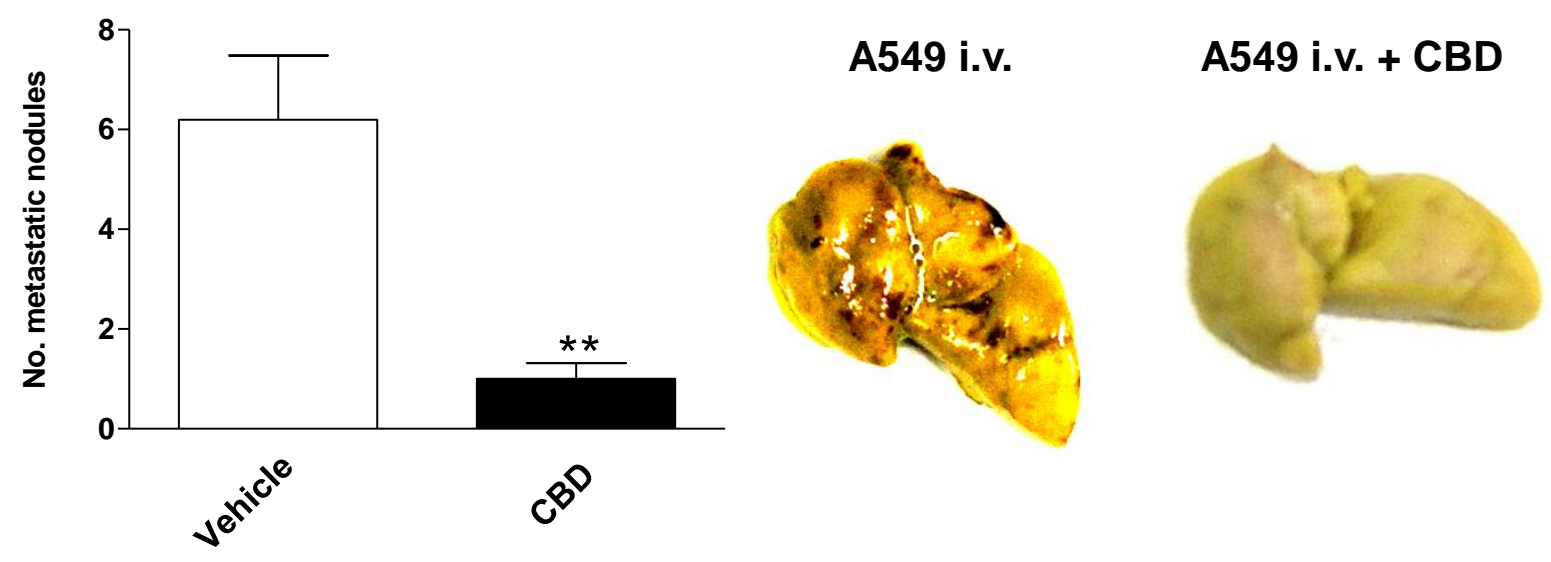

B
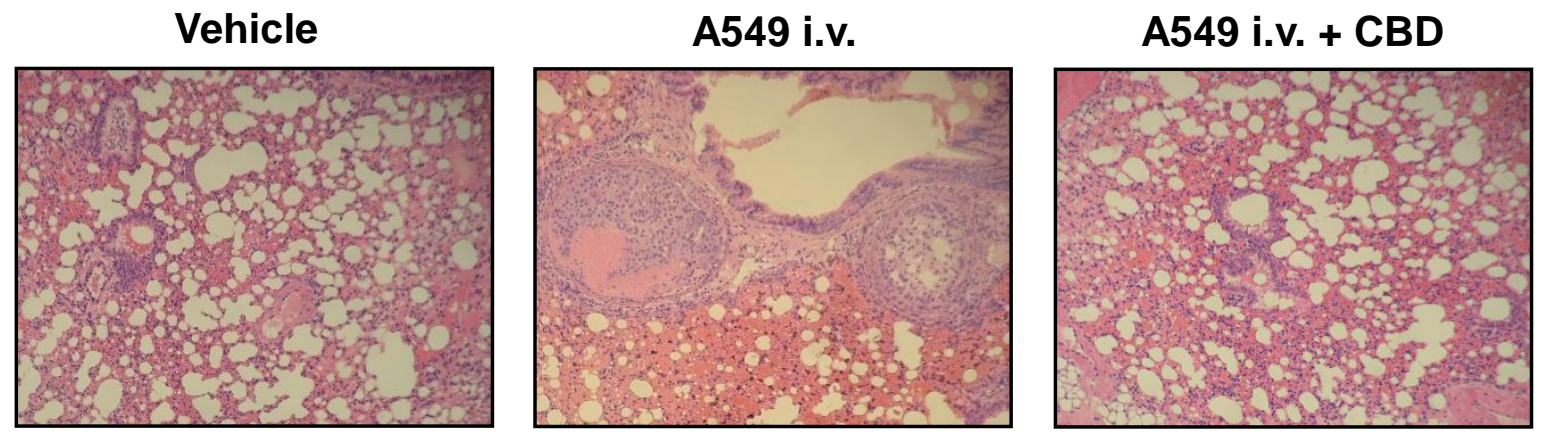

Fig. 7 


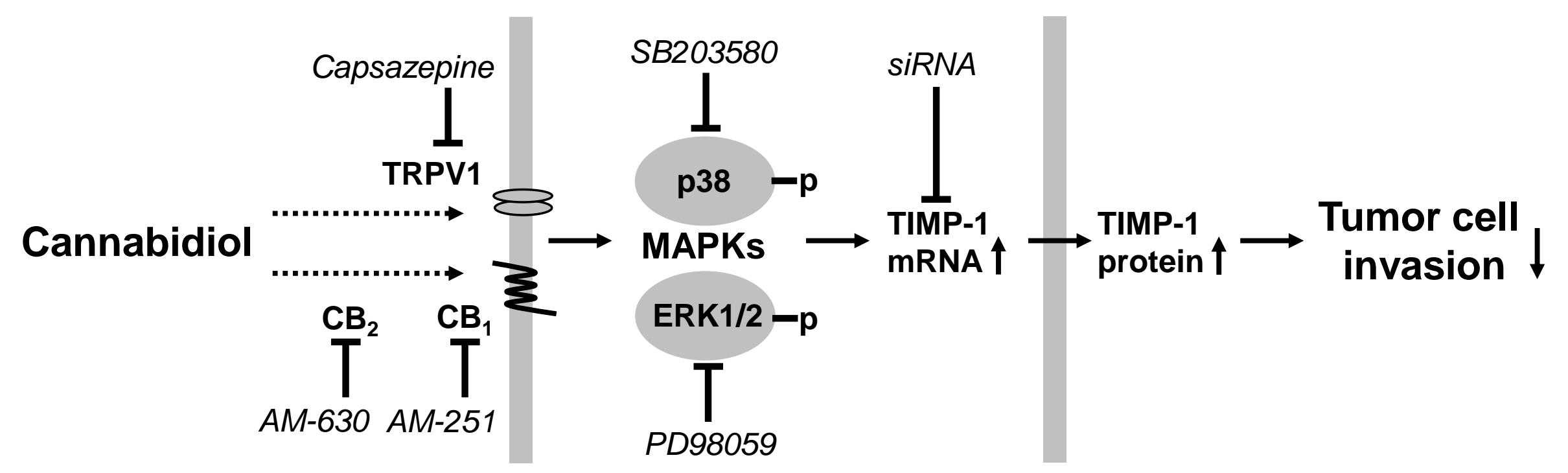

